\title{
Les Brachiopodes du Jurassique inférieur et moyen en Tunisie centrale (Axe Nord-Sud). Un nouveau témoin du Domaine paléobiogéographique ouest-téthysien
}

\author{
Philippe FAURÉ \\ Centre d'ACP, 47 rue Théron Périé, BP 30205, \\ F-81104 Castres cedex (France) et \\ Muséum d'Histoire naturelle de Toulouse, \\ allées Jules-Guesde, F-31000, Toulouse (France) \\ philipfaure@wanadoo.fr \\ Yves ALMÉRAS
}

29 impasse des Mésanges, F-01700 Beynost (France) et Université Claude-Bernard-Lyon1 yves.almeras0827@orange.fr

Najla SEKATNI
Mohammed Sabri ARFAOUI

Fouad ZARGOUNI

Département de Géologie, Faculté des Sciences de Tunis

1060 El Manar II, Tunis (Tunisie)

sgatninejla@yahoo.fr

sabriarfaoui@yahoo.fr

fouadzargouni@yahoo.fr

Publié le 27 mars 2015

Fauré Ph., Alméras Y., Sekatni N., Arfaoui M. S. \& Zargouni F. 2015. - Les Brachiopodes du Jurassique inférieur et moyen en Tunisie centrale (Axe Nord-Sud). Un nouveau témoin du Domaine paléobiogéographique ouest-téthysien. Geodiversitas 37 (1): 31-57. http://dx.doi.org/10.5252/g2015n1a2

\section{RÉSUMÉ}

Dans l'Axe Nord-Sud tunisien, les coupes levées sur le Jebel Sidi Khalif (Khechem El Kelb) et le Châabet El Attaris ont fourni d'abondantes faunes de brachiopodes stratigraphiquement bien repérées dans le Toarcien inférieur-moyen (Jurassique inférieur) et le Jurassique moyen. Les espèces caractérisent, à la fois, les Marges sud et nord de la Téthys occidentale, mais aussi la Bioprovince nord-ouest européenne. Quelques formes d'affinités arabiques s'y ajoutent au Dogger. Ces brachiopodes (19 espèces appartenant à 15 genres) sont décrits et figurés pour la première fois, aucun témoin de ces faunes n’ayant été étudié

MOTS CLÉS

Téthys,

Tunisie,

Jurassique inférieur et

moyen,

brachiopodes,

ammonites,

biostratigraphie,

paléoenvironnements,
paléogéographie. à ce jour sur la Marge nord-africaine, à l'Est de l'Algérie occidentale. Au Toarcien, la Tunisie constitue un nouveau jalon du domaine biogéographique ouest-téthysien, entre Maroc et Algérie occidentale, d'une part, et la bioprovince arabique, d'autre part. Le Jurassique moyen correspond à une période de non différenciation des provinces fauniques et ce n'est qu'à partir du Callovien que les brachiopodes d'influence arabique ou arabo-malgache coloniseront les plates-formes ouest téthysiennes. Les résultats de cette publication concernent la biostratigraphie des brachiopodes de l'Axe Nord-Sud, les paléoenvironnements dans lesquels ils se sont développés, ainsi que d'intéressantes indications sur la paléogéographie de la Tunisie. 


\begin{abstract}
The Brachiopods in the Central Tunisia (North-South Axis). A new evidence of the Western-Tethyan paleobiogeographic Realm.

In the Tunisian North-South Axis, sections surveying on the Sidi Khalif (Kechem El Kelb) and on the Châabet El Attaris Jebels have provided abundant brachiopod faunas stratigraphically well located in the Lower-Middle Toarcian (Lower Jurassic) and in the Middle Jurassic. The collected species characterize at once the Southern and the Northern Margins of the Western Tethys, but also north-western european Bioprovince and some taxa of Arabic origin must be added in the Middle Jurassic. These brachiopods (19 species referred to 15 genera) are described and figured for the first time, any evidence having never be mentioned until nowadays on the North-African Margin, at East of Western Algeria. So, during the Toarcian, Tunisia plays a new link between Morocco and Western Algeria on the one hand and Arabic Bioprovince on the other hand. The Bajocian-Bathonian agrees with a period of non differentiated bioprovinces and it is from to the Callovian onwards that the brachiopod faunas of Arabic and Ethiopian origin will settle on Southern Tunisian Platforms. The results of this paper deal with the biostratigraphical data on Brachiopods, paleoenvironments where they lived and important indications on the paleogeography of Tunisia.
\end{abstract}

\section{INTRODUCTION}

En Tunisie centrale, l'Axe Nord-Sud, est un axe structural de direction méridienne qui s'étend sur $70 \mathrm{~km}$, entre le Jebel El Haouareb ( $45 \mathrm{~km}$ au Sud-Ouest de Kairouan) et le Jebel Rhéouis (15 km à l'Est de Sidi Bou Zid) (Fig. 1A). Le long de cette chaîne s'égrènent plusieurs massifs constitués d'une série jurassique et crétacée, monoclinale, à fort pendage vers l'Ouest, à tectonique assez complexe dans le détail. Le Jebel Nara y occupe la position centrale (Fig. 1B). Le Jurassique affleure de façon discontinue à leur pied oriental.

La série jurassique atteint $500 \mathrm{~m}$ d'épaisseur. Elle est constituée de trois ensembles lithologiques, correspondant aux trois membres de la Formation Nara définie par Burollet (1956) : une assise calcaréo-dolomitique inférieure pour laquelle Castany $(1951,1952)$ admet un âge liasique ; un ensemble argilo-carbonaté médian dans lequel le Bajocien est ponctuellement identifié par Schoeller (1937) ; un ensemble dolomitique supérieur daté par sa seule position au-dessous d'un Jurassique terminal célèbre pour sa richesse en ammonites pyriteuses (Tithonique supérieur à Berriasien) (ArnouldSaget 1951; Castany 1951). Bonnefous (1972), synthétisant de nombreux rapports pétroliers restés inédits, admet que le Jurassique y est complet et que tous les étages sont représentés. Les nombreuses ammonites récoltées par Soussi (Soussi et al. 1991, 2000 ; Soussi 2002) révèleront son caractère condensé, lacunaire et discontinu, entre le Pliensbachien et le Callovien.

Dans les récoltes de Peybernès et al. (1995) nous avons identifié dès 1995 un certain nombre de brachiopodes, en particulier "Stolmorhynchia bouchardi et Pseudogibbirhynchia gr. jurensis-moorei ", espèces bien connues dans le Toarcien d'Europe occidentale et du Maghreb occidental. Rakus \& Guex (2002), dans une annexe peu connue de leur ouvrage, citent des brachiopodes aux affinités identiques, déterminés par Ager, ajoutant aux espèces déjà citées « Homoeorhynchia meridionalis, Lobothyris jauberti, L. pyrenaica,... ». De telles associations sont absentes de Tunisie septentrionale où des brachiopodes de "type alpin » sont seuls représentés (Fauré et al. 2007).

Seulement cités par ces auteurs, parmi d'autres fossiles, les brachiopodes de l'Axe Nord-Sud n'ont jamais été étudiés sur le plan biostratigraphique. Leurs affinités paléobiogéographiques n’avaient jamais été comparées aux faunes désormais bien connues sur les marges de la Téthys occidentale (Alméras \& Fauré 2000, 2008; Alméras et al. 2007a), ce qui justifie de nouvelles recherches.

Ces nouvelles investigations nous ont confirmé l'abondance des brachiopodes, en particulier sur les coupes les plus méridionales de l'Axe Nord-Sud où les couches de l'intervalle ToarcienBathonien se sont montrées plus dilatées, plus complètes et dont les paléoenvironnements semblent plus favorables aux brachiopodes que dans les coupes situées plus au Nord où les faciès apparaissent fréquemment trop condensés. Les coupes du Jebel Sidi Khalif (Khechem El Kelb) (Soussi 2002; Rakus \& Guex 2002) et du Châabet El Attaris (Peybernès et al. 1995) se sont montrées les plus riches (Fig. 1B). La succession des brachiopodes y est confrontée au cadre biostratigraphique zonal donné par de nouvelles récoltes d'ammonites, venant ainsi compléter les datations de Soussi (Soussi et al. 1991, 2000 ; Soussi 2002) et, pour le Toarcien, de Rakus \& Guex (2002).

\section{STRATIGRAPHIE}

Plus de $200 \mathrm{~m}$ de calcaires dolomitiques azoïques rapportés au Lias inférieur (Fm Oust) forment le soubassement des couches fossilifères. Leur partie sommitale, rarement datée de la zone à Demonense (Pliensbachien inférieur) (Soussi et al. 1991; Rakus \& Guex 2002), est surmontée par une importante discontinuité sédimentaire. Les couches argilo-carbonatées sus-jacentes représentent l'intervalle Pliensbachien supérieurBathonien moyen. Elles sont attribuées aux trois Formations Châabet El Attaris, Guemgouma et Khechem El Kelb (Néri et al. 1991 ; Soussi 2002). 


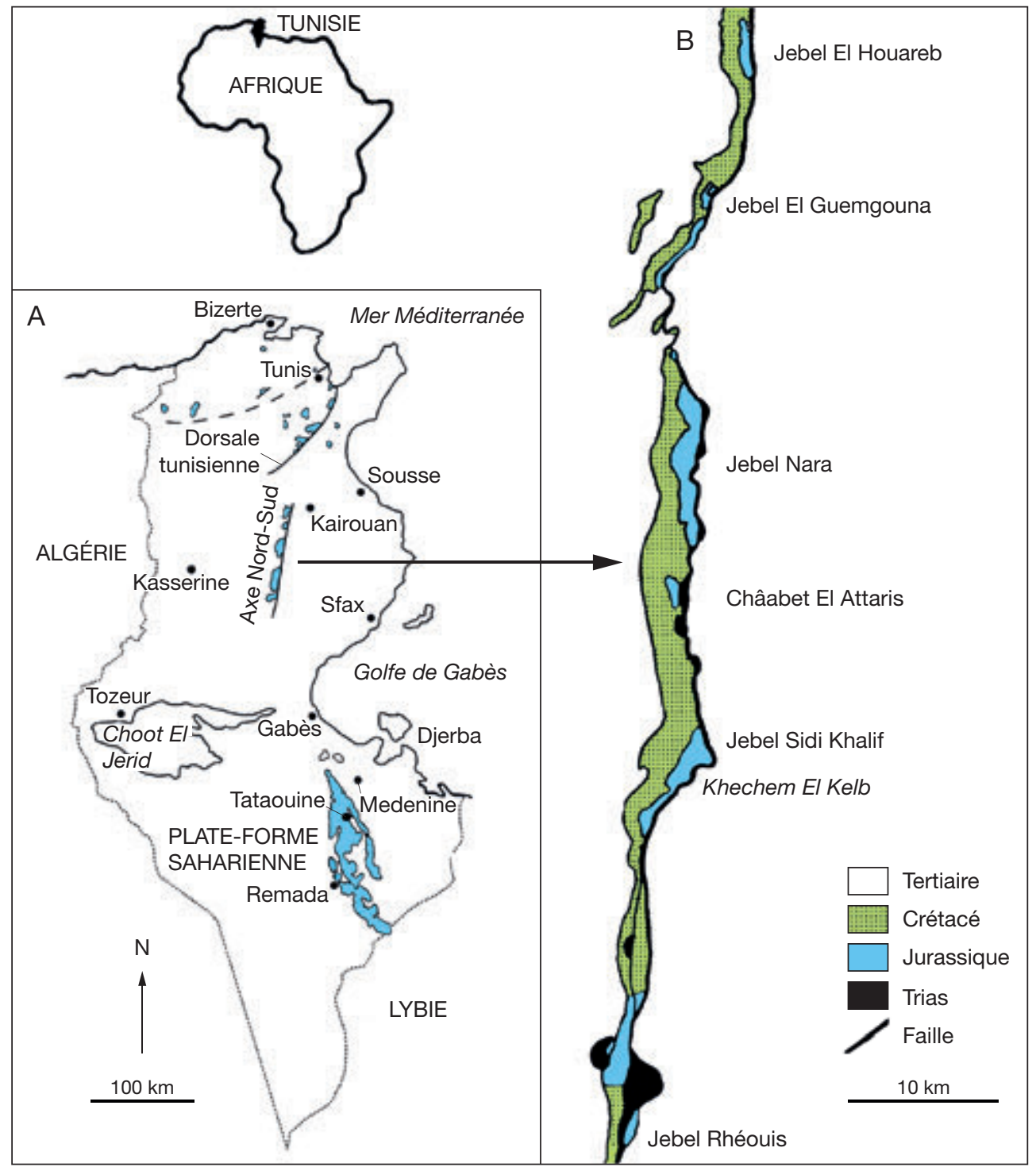

FIG. 1. - A, carte géologique synthétique de la Tunisie et localisation des principaux affleurements de Jurassique ; B, carte structurale schématique de l'Axe Nord-Sud.

\section{Coupe du Jebel Sidi Khalif}

La coupe est relevée sur le versant oriental du jebel, au lieu-dit Khechem El Kelb, $10 \mathrm{~km}$ au Nord de Faid. Les couches y affleurent sur une butte témoin avec un léger pendage vers le Nord. Sur son versant Sud (coupe KEK) et sur son flanc Est (coupe KEKE), les ensembles lithostratigraphiques suivants sont relevés, avec de bas en haut (Fig. 2).

\section{Formation Châabet El Attaris}

Sur 11,5 m d'épaisseur, on distingue :

1) Marnes verdâtres à nodules de limonite intercalées de bancs de calcaires roux, microlité, en bancs décimétriques délités en plaquettes $(1,5 \mathrm{~m})$ à rares empreintes d'Arieticeratinae dont Emaciaticeras sp. gr. emaciatum (Catullo, 1853) du Pliensbachien supérieur, zone à Emaciatum. Cet ensemble est surmonté par 0,30 cm de calcaire microlité noir, à faciès « schiste carton ", à débris de poissons et rares Dactylioceratidae micromorphes du Toarcien basal (zone à Polymorphum probable). Cet horizon témoigne de fonds réducteurs en rapport avec l'épisode anoxique qui affecte assez généralement le Toarcien de Tunisie (Soussi et al. 1990). 2) Marnes beiges ou verdâtres, homogènes, intercalées de bancs noduleux de calcaire argileux beige $(8 \mathrm{~m})$. Les brachiopodes se concentrent parfois en niveaux carbonatés dont certains sont de véritables biostromes. Le plus souvent, ils sont dispersés dans les marnes. Celles-ci renferment quelques ammonites pyriteuses alors que les bancs renferment de gros moules internes carbonatés. Nous avons distingué les niveaux de brachiopodes suivants, de bas en haut (Fig. 2) :

- Niveau 1 : biostrome à très nombreux Soaresirhynchia bouchardi (Davidson, 1852) et $S$. rustica (Dubar, 1931);

- Niveaux 2 et $3:$ Pseudogibbirhynchia jurensis (Quenstedt, 1858), Quadratirhynchia vasconcellosi (Choffat in Dubar, 1931), Telothyris jauberti (Deslongchamps, 1863) et, niveau 2, les ammonites Hildaites subserpentinum Buckman, 1921, 


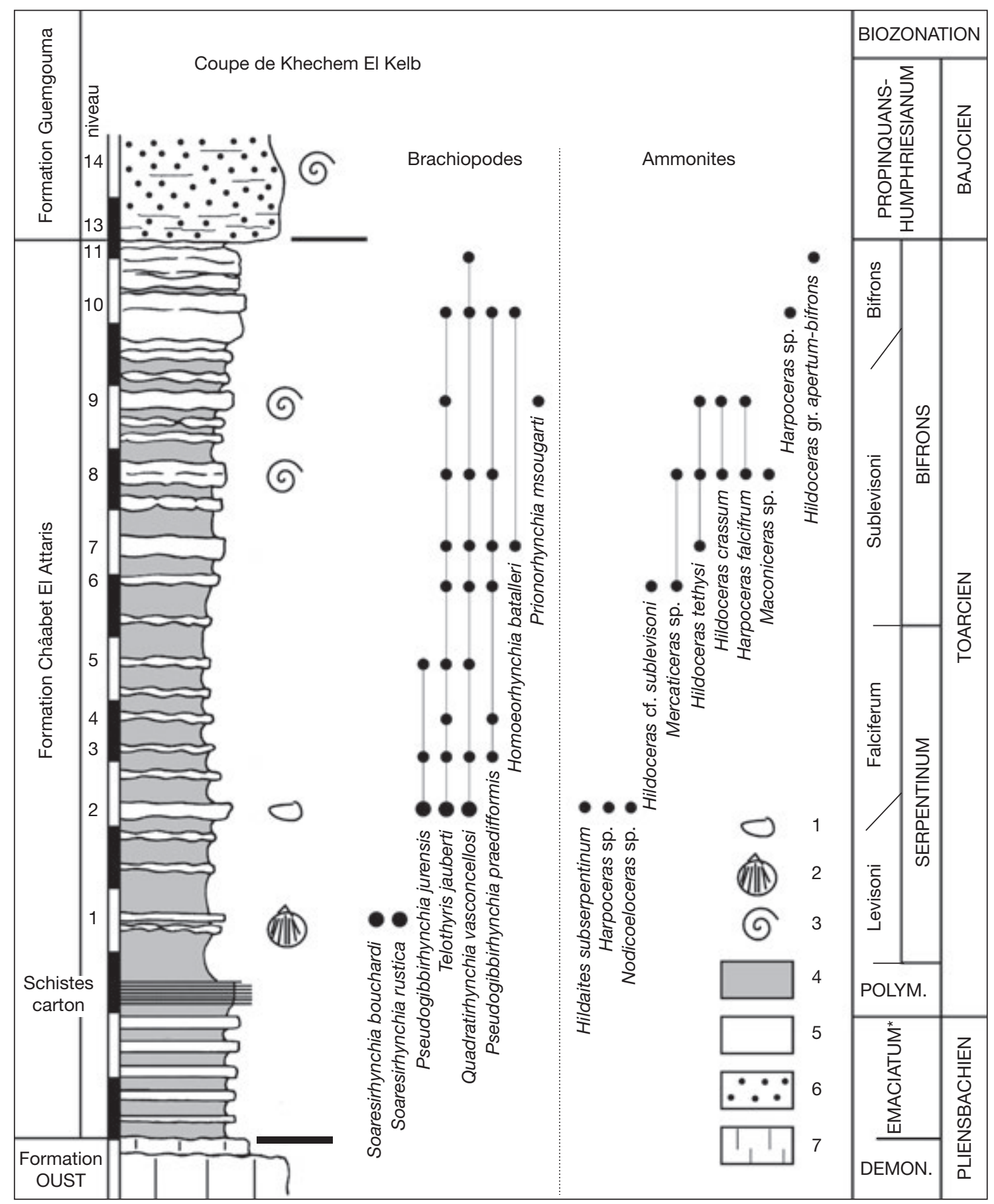

FIG. 2. - Le Toarcien du Jebel Sidi Khalif, coupe de Khechem El Kelb, répartition des brachiopodes et des ammonites ; la biozonation des ammonites est celle du Groupe Français d'étude du Jurassique (1997). Légende : 1, biostromes de térébratulidés ; 2 , biostromes de rhynchonellidés ; 3 , niveaux condensés à ammonites ; 4 , marne ; 5 , calcaire argileux ; 6 , calcaire ferrugineux oolithique ; 7 , calcaire.

Nodicoeloceras sp. et Harpoceras sp., de la zone à Serpentinum, sous-zone à Levisoni;

- Niveaux 4 à 10 : Pseudogibbirhynchia praedifformis (Flamand, 1911), Telothyris jauberti (Deslongchamps, 1863), Pseudogibbirhynchia jurensis (Quenstedt, 1858), Quadratirhynchia vasconcellosi (Choffat in Dubar, 1931). Homoeorhynchia batalleri (Dubar, 1931) et Prionorhynchia msougari Rousselle, 1973 semblent prédominer au sommet de cette assise (niveau 8).
Dès le niveau 6, les ammonites Maconiceras sp. et Hildoceras sp. juv. évoquent la zone à Bifrons. Les niveaux 8 et 9 sont des bancs condensés, très riches en ammonites de la sous-zone à Sublevisoni aux tests imbriqués: Hildoceras tethysi Geczy, 1967, H. crassum Mitzopoulos, 1930, Mercaticeras sp., H. falciferum (Sowerby, 1820) et Maconiceras sp. 3) Calcaire argileux beige bioturbé en bancs noduleux, à surface irrégulière, séparés par des lits de marne d'épaisseur décroissante $(2 \mathrm{~m})$ à rares Quadratirhynchia vasconcellosi 


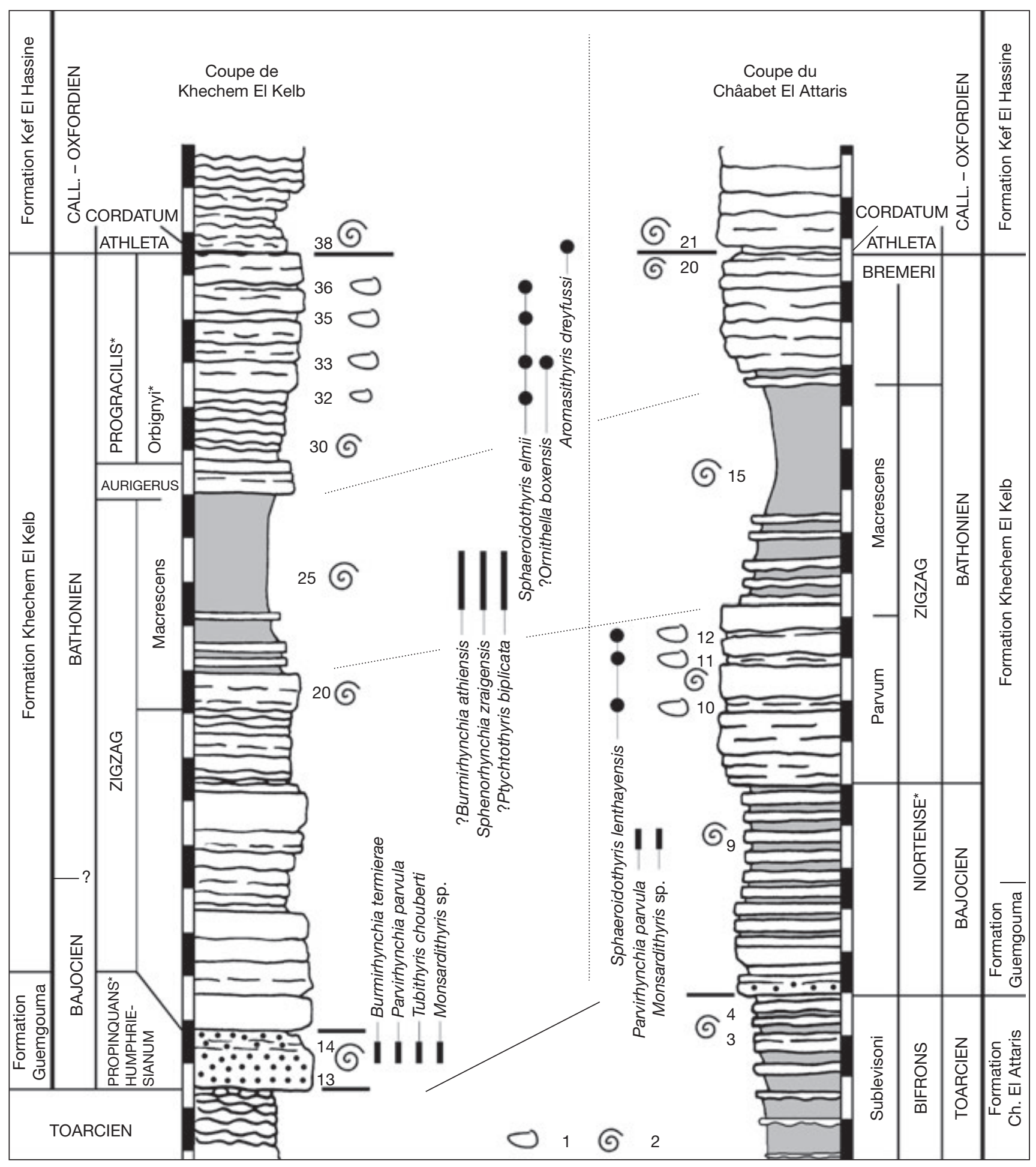

FIG. 3. - Le Jurassique moyen (Bajocien à Callovien) de la partie centrale de l'Axe Nord-Sud. Comparaison des coupes de Khechem El Kelb (Jebel Sidi Khalif) et du Châabet El Attaris. Répartition des brachiopodes dans le cadre zonal donné par les ammonites ( ${ }^{*}$ nouvelle datation apportée par le présent travail). Légende identique à la Fig. 2 sauf : 1, biostromes de brachiopodes ; 2, ammonites ayant permis une datation.

(Choffat in Dubar, 1931). Les ammonites indiquent la sous-zone à Bifrons avec Harpoceras sp. (niveau 10) et Hildoceras gr. apertum-bifrons (niveau 11) dans le mince niveau phosphaté discontinu sommital qui matérialise la lacune de la plus grande partie du Toarcien et de l'Aalénien.

\section{Formation Guemgouma}

Calcaires ferrugineux en bancs irréguliers, discontinus, très riches en oolithes ferrugineuses $(1,5 \mathrm{~m})$. Ils renferment une faune abondante, condensée, remaniée et réélaborée de bivalves, gastéropodes et ammonites au sein de laquelle les 
brachiopodes sont peu nombreux : Parvirhynchia parvula (Deslongchamps, 1862), Burmirhynchia termierae Rousselle, 1965 pars, sensu Alméras \& Sadki (1992), Monsardithyris sp., Tubithyris chouberti Rousselle, 1965.

Les ammonites du Bajocien inférieur permettent de distinguer deux niveaux :

- Niveau 13 : Witchellia sp. ind. aff. sutneri (Branco, 1879) et Emileia gr. brocchii (Sowerby, 1818) (sous-zone à Propinquans);

- Niveau 14 : Dorsetensia romani (Oppel, 1857), Pelekodites sp. aff. sulcata Buckman, Strigoceras (S.) pseudostrigifer (Maubeuge, 1955), Skirroceras macrum (Quenstedt, 1886), Stephanoceras gr. umbilicatum (Quenstedt, 1886), Teloceras sp., Normannites gr. orbignyi Buckman, 1908, Chondroceras gr. evolvescens Waagen, 1867 (sous-zone à Humphriesianum).

\section{Formation Khechem El Kelb}

Elle est matérialisée par deux ensembles carbonatés (a, c) séparés par une assise argileuse (b) $(19 \mathrm{~m})$ :

a) calcaires clairs $(9,5 \mathrm{~m})$, en bancs réguliers, bioturbés, à Zoophycos, peu fossiliferes et ne renfermant aucun brachiopode dans cette localité ( $8 \mathrm{~m}$ ). Au sommet (niveau 20), Oraniceras hamyanense (Flamand, 1911) indique le Bathonien inférieur, zone à Zigzag (in Soussi 2002);

b) argiles jaunes à concrétions et fossiles pyriteux, intercalées de plusieurs bancs carbonatés $(4 \mathrm{~m})$, dans lesquels les brachiopodes sont représentés par (niveau 25) : Sphenorhynchia zraigensis (Dareste De La Chavanne, 1930) et ? Burmirhynchia athiensis Rousselle, 1965, ? Ptyctothyris biplicata (Rousselle 1965).

Les ammonites pyriteuses indiquent les zones à Zigzag (sous-zone à Macrescens) et à Aurigerus (sous-zone à Recinctus), avec Oxycerites yeovilensis Rollier, 1911, Morphoceras (Morphoceras) jactatum (Buckman, 1920), M. (Ebrayiceras) sulcatum (Hehl in Zieten, 1830), Cadomites sp., Procerites sp. Asphinctites replictus (Buckman, 1922), Polysphinctites polysphinctus Buckman, 1922;

c) calcaires gris, en bancs décimétriques, bioturbés, à Zoophycos $(5,5 \mathrm{~m})$. Les brachiopodes s'y regroupent en quatre niveaux distincts (niveaux 32, 33, 35, 36) à faune monospécifique de Sphaeroidothyris elmii Alméras \& Moulan, 1988. ?Ornithella boxensis Muir-Wood, 1936 y est aussi présente dans le niveau 33.

Nous avons trouvé à la base (niveau 30) Cadomides (C.) orbignyi (de Grossouvre, 1930) de la zone à Progracilis (souszone à Orbignyi). Au sommet (niveaux 36 et 37), Soussi (Soussi et al. 1991; Soussi 2002) a signalé une association de la zone à Bremeri avec, notamment, Cadomides (C.) bremeri Tsereteli, 1968, Hecticoceras (Prohecticoceras) ochraceum Elmi, 1971.

Une discontinuité marquée par un hard-ground perforé, karstifié, limite cette assise, à son sommet. Au-dessus, on observe des calcaires noduleux matérialisant un intervalle condensé avec ammonites du Callovien moyen et supérieur ( $1 \mathrm{~m}$ ) et, dans le niveau 38, le brachiopode Aromasithyris dreyfussi Boullier, 1976. L'Oxfordien inférieur lui succède (zone à Cordatum) (Soussi 2002). Il est visible sur $2 \mathrm{~m}$, avant que le front de dolomitisation n'efface la texture des roches.

\section{COUPE DU CHÂABET El ATTARIS}

La coupe (CHA) est relevée sur le versant oriental du Jebel, face au Sebkhet El Bahira. De part et d'autre d'un oued qui dévale des pentes du Jebel, le Toarcien et le Jurassique moyen sont épargnés, sur quelques dizaines de mètres carrés, par l'intense dolomitisation qui affecte presque partout les couches et efface texture des roches et contenu faunique (Fig. 3).

\section{Formation Châabet El Attaris}

La coupe débute, dans la partie moyenne de la formation, avec des marnes beiges intercalées de bancs de calcaire noduleux. Trois niveaux de brachiopodes y sont repérés :

- niveau 1 : Pseudogibbirhynchia jurensis (Quenstedt, 1858), Quadratirhynchia vasconcellosi (Choffat in Dubar, 1931), Telothyris jauberti (Deslongchamps, 1863) avec, à la base, Hildaites serpentiniformis Buckman, 1919 de la zone à Serpentinum; - niveaux 3 et 4 : Pseudogibbirhynchia praedifformis (Flamand, 1911), Homoeorhynchia batalleri (Dubar, 1931), Quadratirhynchia vasconcellosi (Choffat in Dubar, 1931), Telothyris jauberti (Deslongchamps, 1863), avec Hildoceras tethysi Geczy, 1967, H. sublevisoni Fucini, 1919, Harpoceras mediterraneum Pinna, 1968 et $H$. subexaratum Bonarelli, 1899, indiquant la zone à Bifrons, sous-zone à Sublevisoni.

\section{Formation Guemgouma}

La formation se réduit ici à quelques bancs de calcaire roux partiellement dolomitisés, à quelques oolithes ferrugineuses, sans fossile.

\section{Formation Khechem El Kelb}

Les trois ensembles lithologiques déjà distingués à Khechem El Kelb y sont retrouvés $(17,5 \mathrm{~m})$ :

1) Calcaires argileux en bancs réguliers ( $4 \mathrm{~m}$ ) séparés par des lits de marnes passant progressivement à des calcaires clairs bioturbés $(6 \mathrm{~m})$, en bancs décimétriques réguliers à Zoophycos. - Niveau 9: Parvirhynchia parvula (Deslongchamps, 1862) et Monsardithyris sp. et les ammonites Oppelia sp. et Spiroceras sp. du Bajocien supérieur, zone à Niortense.

- Niveaux 10, 11, 12 : Trois biostromes de brachiopodes livrent une faune monospécifique de Sphaeroidothyris lenthayensis (Richardson \& Walker, 1907) et des ammonites du Bathonien inférieur, sous-zone à Parvum (Lobosphinctes aff. incognitus (Arkell, 1958) et Planisphinctes sp. in Soussi, 2002). 2) Argiles jaunes recouvertes d'éboulis $(4,5 \mathrm{~m})$, avec ammonites pyriteuses de la zone à Zigzag (sous-zone à Macrescens) avec (niveau 15) : Oxycerites yeovilensis Rollier, 1911, Morphoceras (Morphoceras) jactatum (Buckman, 1920), Cadomites sp. Elles n'ont pas fourni de brachiopodes.

3) Calcaires roux, en bancs ondulés, compacts, sans fossile, surmontés par un niveau glauconieux, oolithique condensé à ammonites de la zone à Bremeri (in Soussi 2002) (niveau 20), précédant une importante discontinuité marquée par un hard-ground.

Les calcaires sus-jacents appartiennent au Callovien supérieur (zone à Athleta) (niveau 21) avec Groussouvria sp., Subgroussouvria sp., ? Orionoides sp. Erymnoceras (E.) sp. Holcophylloceras mediterraneum (Neuman, 1871), Sowerbyceras sp. (in Peybernès et al. 1995). Ils sont recouverts par des niveaux condensés de l'Oxfordien inférieur. 


\section{SYSTÉMATIQUE}

Classe BRACHIOPODA Duméril, 1806

Ordre RHYNCHONELLIDA Kuhn, 1949

Super-famille PugnaCoIDEA Rzonsnitskaia, 1956

Famille BASILIOLIDAE Cooper, 1959

Sous-famille BASILIOLINAE Cooper, 1959

Genre Soaresirhynchia Alméras, 1994

ESPÈCE TYPE. - Rhynchonella bouchardi Davidson, 1852 par désignation originale (Alméras 1994: 26).

Soaresirhynchia bouchardi (Davidson, 1852)

(Figs 4A-F; 5A-C)

Rhynchonella bouchardi Davidson, 1852: 82, pl. 15, figs 3-5.

Soaresirhynchia bouchardi-Dubar 1931: 133, pl. 2, figs 19-28. Elmi et al. 1985: 23, pl. 2, figs 1-4. - Alméras \& Fauré 2000: 113, pl. 12, figs 1-10, pl. 13, figs 7-14. - Alméras et al. 2007a: 58, pl. 3, figs 3-9; 2010a: 21, pl. 1, figs 1-3, pl. 5, figs 6, 7.

MatéRIEL eXAminé. - Khechem El Kelb, niveaux KEK.1(2010) (68 exemplaires) et KEK.1(2011) (63 exemplaires).

ÂGE ET RÉPARTITION. - Espèce-indice de la sous-zone à Soaresirhynchia bouchardi corrélée dans l'échelle chronostratigraphique standard des ammonites avec la sous-zone à Elegantulum (zone à Serpentinum = zone à Levisoni de la province méditerranéenne).

Plates-formes de l'Europe moyenne : Angleterre (Somerset, Dorset), France (Bordure sud du Massif Armoricain), Allemagne (Wurtemberg).

Domaine nord-téthysien occidental : France (Provence méridionale, Pyrénées ariégeoises, Comminges, Pyrénées basco-béarnaises), Espagne (Zone sud-pyrénéenne, Pedraforca, Sierras Marginales, Cordillère Ibérique, Andalousie, Baléares), Portugal (Sous-bassin nord-lusitanien).

Domaine sud-téthysien occidental : Maroc (Moyen-Atlas, Haut-Atlas central, Beni Snassen), Algérie occidentale (Monts des Traras, de Rhar Roubane, de Saïda et secteur de Takhmaret).

DESCRIPTION

Espèce de petite taille, de contour transversalement ovale, généralement plus large que long. Convexité très variable, avec une valve dorsale presque toujours plus renflée que la valve ventrale. Uniplication frontale presque toujours symétrique. Le sinus ventral reste peu profond, il est même parfois absent. La partie postérieure des valves est toujours lisse. 4 à 12 côtes arrondies, assez grossières dont 2 à 6 se situent sur le pli médian dorsal. Crochet massif, presque toujours crêté latéralement. Foramen le plus souvent ovale. Plaques deltidiales séparées.

La forme type de l'espèce avec 2 côtes sur le pli médian dorsal (Fig. 4A, B) est rare (14 exemplaires sur 131). Les coquilles avec 3 côtes sur le pli médian (Fig. 4C-E) sont nombreuses (50 exemplaires). Le morphe prerenzi (Fig. 5A-C) est également bien représenté ( 55 exemplaires). Ce morphotype se différencie par son crochet plus court, recourbé, par ses coquilles un peu plus larges et par une costulation un peu plus fine et légèrement plus dense. Ce morphotype connaîtra son apogée au Toarcien supérieur avec Soaresirhynchia renzi (Choffat).
Soaresirhynchia rustica (Dubar, 1931)

(Fig. 5D, E)

Rhynchonella bouchardi var. rustica Dubar, 1931: 35, pl. 2, figs 30, 31.

Soaresirhynchia rustica - Alméras 1994: 64, pl. 3, figs 1-13. Alméras \& Fauré 2000: 115, pl. 13, figs 1-6, 15, 16. - Fauré et al. 2004: 58, pl. 3, fig. 8. — Alméras et al. 2007a: 65, pl. 3, figs 17-23; 2010a: 22, pl. 1, fig. 4.

Matériel eXaminé. - Khechem El Kelb, niveau KEK.1(2011) (8 exemplaires).

ÂGE ET RÉPARTITION. - Même extension verticale et même répartition géographique que Soaresirhynchia bouchardi.

\section{DESCRIPTION}

Soaresirhynchia rustica se différencie de $S$. bouchardi par ses coquilles de plus grandes dimensions au stade adulte, un peu plus larges et surtout moins épaisses ainsi que par une uniplication frontale moins élevée. Les deux coquilles de même taille (Fig. 5D, E) illustrent une costulation plus ou moins dense (10 et 15 côtes).

Sous-famille PAMIRORHYNCHIINAE Ovcharenko, 1983

Genre Pseudogibbirhynchia Ager, 1962

ESPÈCE TYPE. - Rhynchonella moorei Davidson, 1852, par désignation originale (Ager 1962: 108).

Pseudogibbirhynchia jurensis (Quenstedt, 1858) (Fig. 6A-C)

Terebratula jurensis Quenstedt, 1858: 287, pl. 41, fig. 33 (lectotype), non figs 34,35 .

Rhynchonella jurensis - Davidson 1878: 224, pl. 27, figs 24-27. Haas 1889: 9, pl. 2, fig. 11. — Dubar 1931: 23, pl. 2, figs 13, 14.

Pseudogibbirhynchia jurensis - Ager 1962: 112, pl. 10, figs 1, 2. Alméras 1996a: 8, fig. 1(8-12). - Alméras \& Bécaud 2002: 23, pl. 1, fig. 13. - Alméras et al. 2010a: 24, fig. h.t. 1, pl. 1, figs 9, 10. - García Joral et al. 2011: fig. 5(8).

Matériel eXAminé. - Khechem El Kelb, niveaux KEK.3(2010) et KEK.9(2010) ; KEK.2(2011) (7 exemplaires) et KEK.5(2011) (2 exemplaires). Châabet El Attaris, niveaux CHA.1 (12 exemplaires) et hors place, CHA.0 (17 exemplaires).

ÂGe et RÉpARTITION. - Toarcien inférieur, zone à Serpentinum, sous-zone à Elegantulum jusqu'au Toarcien moyen, zone à Bifrons, sous-zone à Sublevisoni.

Plates-formes de l'Europe moyenne : Angleterre (Somerset, Oxfordshire, Cotteswolds), Allemagne (Wurtemberg), France (Jura méridional, Mont d'Or lyonnais, Éperon lyonnais).

Domaine nord-téthysien occidental : France (Ardèche, Quercy, Var), Espagne (Zone de Pedraforca, Sierras Marginales septentrionales et méridionales, Catalogne, Cordillère Ibérique), Portugal (Sous-bassin nord-lusitanien).

Domaine sud-téthysien occidental : Maroc (Moyen-Atlas, HautAtlas central et oriental), Algérie occidentale (Ouarsenis, Monts de Rhar Roubane). 

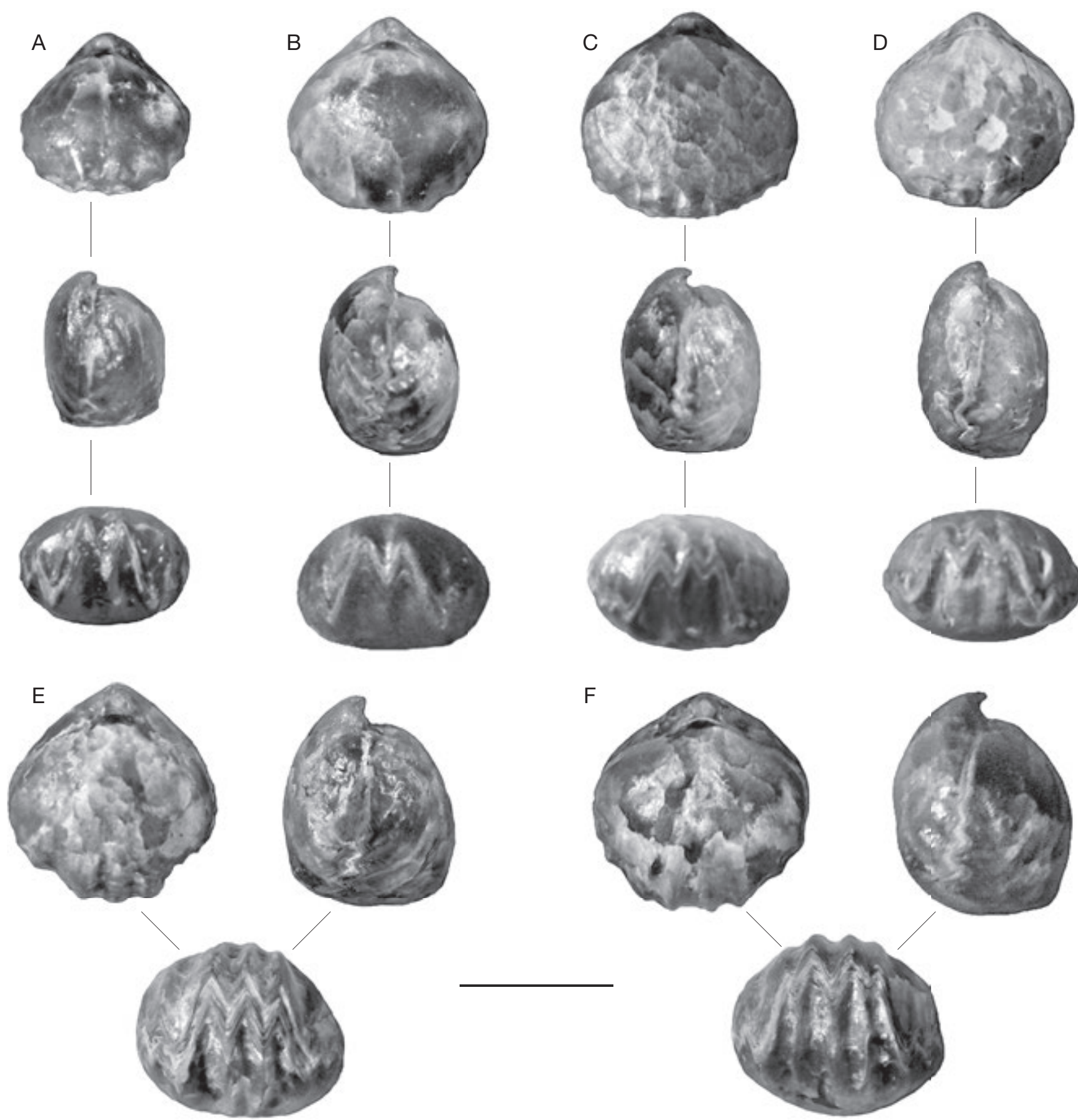

FIG. 4. - Soaresirhynchia bouchardi (Davidson, 1852). Toarcien inférieur, zone à Serpentinum, sous-zone à Elegantulum. Khechem El Kelb, niveau KEK.1. Spécimens avec : A, B, deux côtes, PFT300 (A), PFT301(B) ; C-E, trois côtes PFT302 (C), PFH303 (D), PFT304 (E); F, quatre côtes (PFT305) sur le pli médian dorsal (collection Ph. Fauré). Il est déposé dans les collections de l'Office national des Mines de Tunis. Échelle : $1 \mathrm{~cm}$.

\section{DESCRIPTION}

Coquilles de 7,5 à $13 \mathrm{~mm}$ de longueur, plus larges que longues, de contour subpentagonal arrondi. Valves modérément et presque également convexes, avec un léger aplatissement antérieur sur la valve dorsale. Planoplication frontale symétrique. Pli médian dorsal et sinus ventral ne sont jamais nettement définis. Costulation présente sur la totalité de la surface des valves. 9 à 15 côtes arrondies dont 3 à 6 sur le pli médian dorsal. Petit crochet pointu, subdressé à dressé, sans crêtes latérales nette- ment exprimées. Foramen circulaire ou ovale. Plaques deltidiales séparées. Variabilité de l'espèce illustrée par des coquilles photographiées in Alméras et al. (2010a: fig. h.t. 1).

Pseudogibbirhynchia praedifformis (Flamand, 1911) (Fig. 6D-F)

Rhynchonella praedifformis Flamand, 1911 : 866, pl. 11, fig. 10. - Gourion 1960 : 98, pl. 2, fig. 7. — Alméras et al. 1996 : 153, pl. 2, fig. 7. 

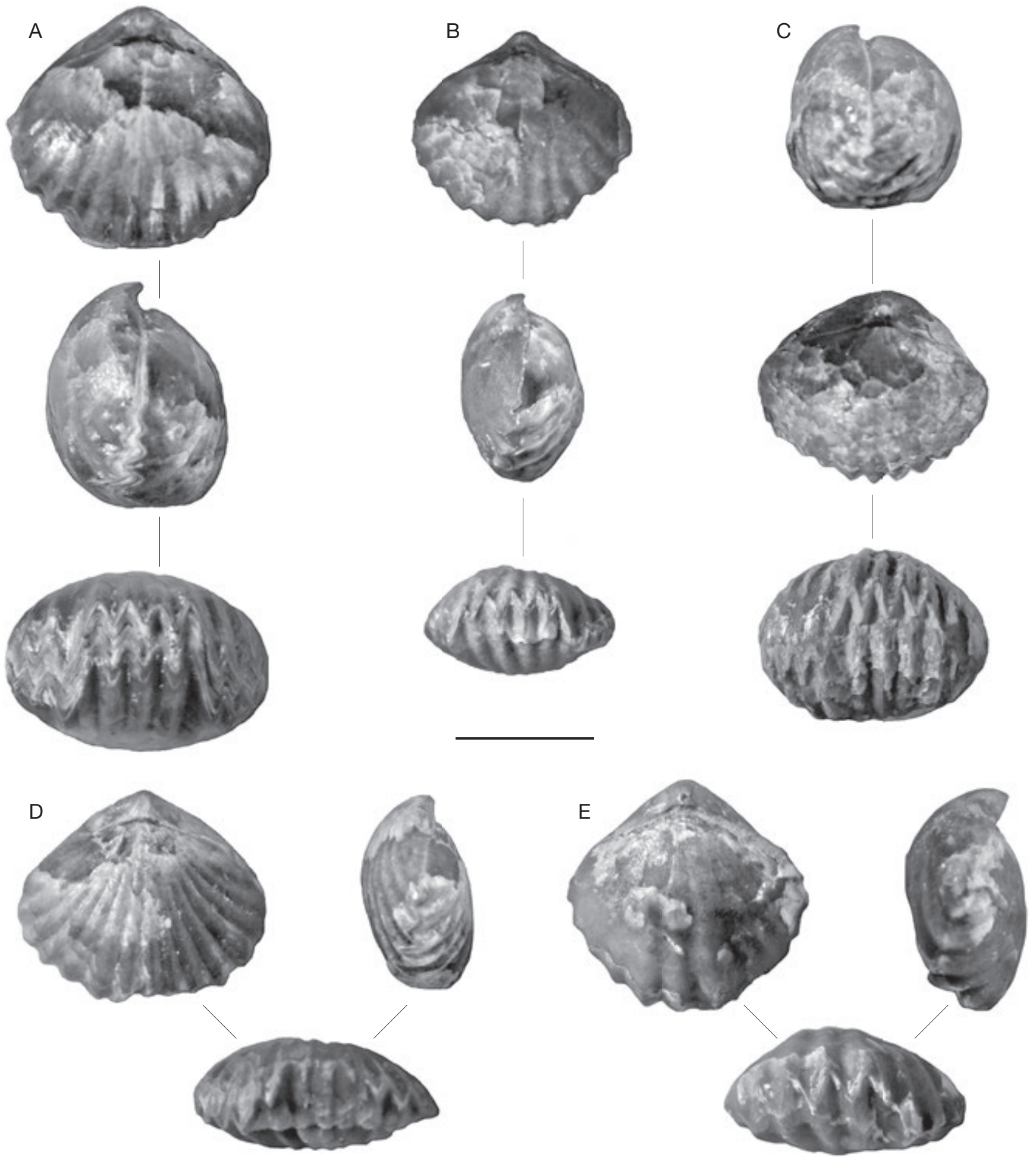

FIG. 5. - A-C, Soaresirhynchia bouchardi (Davidson, 1852), Toarcien inférieur, zone à Serpentinum, sous-zone à Elegantulum : A, Morphe prerenzi (PFT306) ; B, PFT307 ; C, PFT308 ; D, E, Soaresirhynchia rustica (Dubar, 1931), Toarcien inférieur, zone à Serpentinum, sous-zone à Elegantulum, Khechem El Kelb, niveau KEK.1, PFT309 (D), PFT310 (E). Variabilité de la densité de la costulation (Nvd = 15 et 12 côtes). Échelle : $1 \mathrm{~cm}$.

Homoeorhynchia tifritensis praedifformis - Elmi et al. $1985: 25$, pl. 3, fig. 10.

Soaresirhynchia praedifformis - Alméras et al. 2007a : 68, pl. 4, fig. 1.

MatéRIEL EXAMINÉ. — Khechem El Kelb, niveaux KEK.3(2011) (1 exemplaire), KEK.4(2011) (1 exemplaire), KEK.6(2011) (3 exem- plaires), KEK.7(2011) (3 exemplaires), KEK.8(2010) (11 exemplaires), KEK.8(2011) (1 exemplaire), KEK.10(2010)(1 exemplaire); Khechem El Kelb Est, niveaux KEKE.8 (3 exemplaires), KEKE.10.1 (5 exemplaires), KEKE.10.2 (1 exemplaire). Châabet El Attaris, niveaux CHA.3 (1 exemplaire), CHA.4 (6 exemplaires) et, hors place CHA.00 (3 exemplaires). 
ÂGe ET RÉPARTITION. — Portugal : Toarcien moyen, zone à Bifrons, souszone à Sublevisoni sur la rampe carbonatée de Tomar (Alméras et al. 1996). Algérie occidentale : Toarcien moyen, zone à Bifrons, sous-zone à Sublevisoni dans les Monts de Saïda (Sidi-bou-Graïnat, Cherchar, Djebel Keskas), à Takhmaret et à Aïn Balloul (Gourion 1960 ; Alméras et al. 2007a).

\section{DESCRIPTION}

Dimensions, morphologie et densité de la costulation comparables à celles de Pseudogibbirhynchia jurensis. L'espèce praedifformis se différencie aisément par la forte dissymétrie de son uniplication frontale, tantôt dextre, tantôt senestre, qui divise les coquilles en deux lobes latéraux très distincts. Il y a donc absence de pli médian dorsal et de sinus ventral. 9 à 18 côtes. Crochet pointu, subdressé et très élevé au-dessus de l'umbo dorsal. Foramen ovale. Plaques deltidiales séparées.

\section{REMARQUE}

En raison de la similitude de ses caractères internes avec ceux de Soaresirhynchia bouchardi (comparer fig. h.t. 6 et fig. h.t. 3 in Alméras et al. 2007a), l'espèce praedifformis a été récemment rapportée au genre Soaresirhynchia et cela, malgré l'absence de stade postérieur non costé (Alméras et al. 2007a). Les caractères internes de praedifformis et ceux de Pseudogibbirhynchia jurensis ne différant pas sensiblement et les deux espèces étant costées sur l'entière surface des valves, nous préférons rapporter praedifformis au genre Pseudogibbirhynchia. En outre, bien qu'ayant la même extension verticale, ces deux espèces n'ont pas été collectées ensemble.

\section{Super-famille RHYNCHOTETRADOIDEA Licharev, 1956 \\ Famille PRIONORHYNCHIIDAE \\ Savage, Manceñido, Owen, Dagys, 2002 \\ Genre Prionorhynchia Buckman, 1917}

ESPÈCE TYPE. - Terebratula serrata J. De C. Sowerby, 1825, par désignation originale (Buckman 1917: 62).

\section{Prionorhynchia msougari Rousselle, 1973}

(Fig. 7A)

Prionorhynchia msougari formes pentagonale et triangulaire Rousselle, 1973: 137, 142, figs 1-4, 5.

Prionorhynchia msougari-Alméras et al. 1993 : 65, pl. 2, figs 8, 9. Alméras 1996: 29, pl. 3, figs 1-6. — Alméras et al. 2007a: 56, pl. 2, fig. 20.

MATÉRIEL EXAMINÉ. - Khechem El Kelb, niveau KEK.9 (2010), 1 spécimen (Fig. 7A). Dimensions: longueur 13,3 mm; largeur $14,2 \mathrm{~mm}$; épaisseur $11,3 \mathrm{~mm}$.

ÂGE ET RÉPARTITION. — Maroc : Toarcien moyen-?supérieur du Haut-Atlas central et oriental ; Toarcien moyen, zone à Gradata de Foum Ikis, dans le Haut-Atlas central, où l'espèce est associée à Sphaeroidothyris vari (Rollier).

Algérie occidentale : extension verticale plus ancienne dans l'Ouarsenis (association avec les espèces des genres Soaresirhynchia et Telothyris). France : Éperon lyonnais, La Verpillière et Mont d'Or, Toarcien moyen et Toarcien supérieur basal.

\section{DESCRIPTION}

Spécimen d'assez petite taille, de contour pentagonal (bord antérieur rectiligne), de forte épaisseur frontale, avec planareas marquées et comparable à la coquille dessinée par Rousselle (1973: fig. 1a, grossie 1,7 fois). Valve ventrale peu bombée, valve dorsale aplatie au front, d'où absence de pli médian dorsal et de sinus ventral. Costulation fine présente sur le crochet et sur l'umbo dorsal. À l'avant, 10 grosses côtes arrondies dont une s'efface avant d'atteindre le bord antérieur de la valve dorsale. Gros crochet court, recourbé, peu élevé au-dessus de l'umbo dorsal. Très petit foramen circulaire, submésothyride entre de courtes crêtes latérales arrondies du crochet. Plaques deltidiales séparées.

\section{Genre Sphenorhynchia Buckman, 1917}

ESPÈCE TYPE. - Terebratula plicatella J. de C. Sowerby, 1825, par désignation originale (Buckman 1917: 30).

\section{Sphenorhynchia zraigensis \\ (Dareste De La Chavanne, 1930)}

Rhynchonella plicatella var. zraigensis Dareste De La Chavanne, 1930: 74, pl. 4, figs 7-9.

Sphenorhynchia zraigensis - Alméras et al. 2007b : 8, fig. 6(5). Alméras \& Fauré 2008: 639, pl. 5, figs 2-6.

Matériel eXAminé. — Khechem El Kelb, niveau KEK.25.

ÂGE ET RÉPARTITION. - Bajocien supérieur terminal, sous-zone à Bomfordi et Bathonien inférieur, zone à Zigzag et zone à Aurigerus, sous-zone à Recinctus. Maroc : Monts d'Oujda, Moyen-Atlas et Haut-Atlas central. Algérie occidentale : Monts des Traras, de Rhar Roubane et de Saïda. Dernière apparition dans le Bathonien moyen, zone à Bremeri des Monts d'Oujda.

\section{DESCRIPTION}

Un seul spécimen de 18,3 mm de long, déformé mais caractéristique et comparable aux deux coquilles figurées par Alméras \& Fauré (2008: pl. 5, figs 5, 6). Voir variabilité de l'espèce in Alméras \& Fauré (2008: fig. 24).

Super-famille RHYNCHONELlOIDEA Owen \& Manceñido, 2002 Famille RHYNCHONELLIDAE D'Orbigny, 1847 Sous-famille RHYNCHONELLINAE D’Orbigny, 1847

Genre Homoeorhynchia Buckman, 1917

ESPÈCE TYPE. - Terebratula acuta J. Sowerby, 1818 par désignation originale (Buckman 1917: 36).

\section{Homoeorhynchia batalleri (Dubar, 1931)} (Fig. 7B)

Rhynchonella batalleri Dubar, 1931: 25, pl. 1, figs 12-18.

Homoeorhynchia batalleri-Alméras 1996b: 34, pl. 2, figs 7-18, avec la synonymie. - Alméras \& Fauré 2000: 126, pl. 13, figs 21-25, 

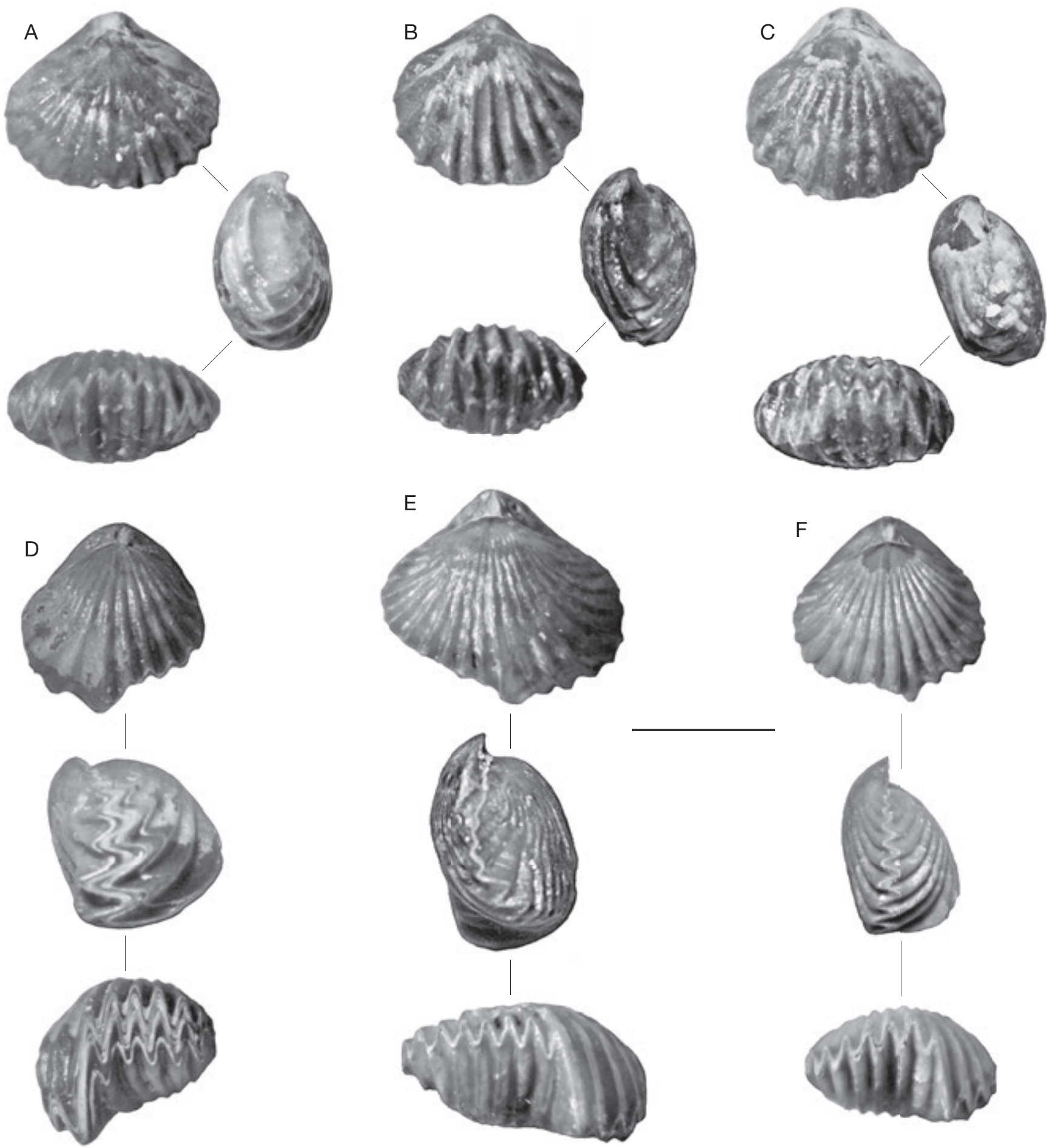

FIG. 6. - A-C, Pseudogibbirhynchia jurensis (Quenstedt, 1852), Toarcien inférieur, zone à Serpentinum, Châabet El Attaris : A, niveau CHA.0, PFT312 ; B, C, niveau CHA.1, PFT313 (B), PFT314 (C) ; variabilité de l'espèce. D-F, Pseudogibbirhynchia praedifformis (Flamand, 1911), Toarcien moyen, zone à Bifrons, sous-zone à Sublevisoni, Khechem El Kelb, niveau KEK.4, PFT315 (D), PFT316 (E), PFT317 (F), variabilité de l'espèce. Échelle : $1 \mathrm{~cm}$.

avec la synonymie. - Alméras et al. 2007a: 70, pl. 4, figs 2-4. García Joral et al. 2011: fig. 5(4).

MATÉRIEL EXAMINÉ. - Khechem El Kelb, niveau KEK.7(2011) (1 exemplaire) ; Khechem El Kelb Est, niveaux KEKE.7 (1 exemplaire), KEKE.10.1 (1 exemplaire). Châabet El Attaris, niveau CHA.3 (1 exemplaire).
ÂGE ET RÉPARTITION. - Espèce-indice de la zone de brachiopode à Homoeorhynchia batalleri et Telothyris jauberti corrélée avec la zone à Serpentinum et avec la zone à Bifrons (sous-zone à Sublevisoni seulement). Large répartition géographique sur les marges nord et sud de la Téthys occidentale.

Maghreb. Maroc : Monts des Zekkara, Moyen-Atlas, Haut-Atlas central. Algérie occidentale : Monts de Saïda, de Rhar Roubane et des Traras, Ouarsenis. 

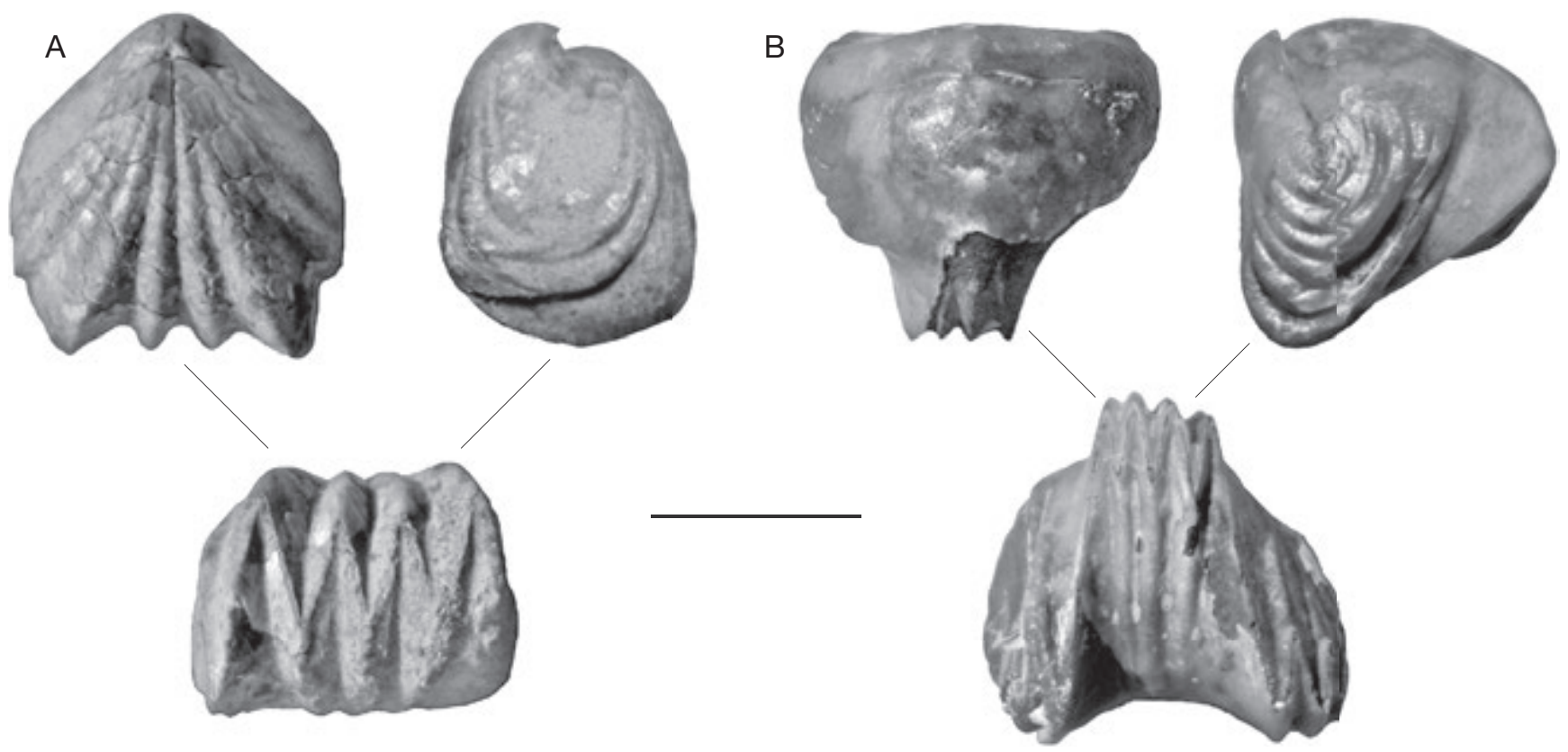

FIG. 7. - A, Prionorhynchia msougari Rousselle, 1973, Toarcien moyen, zone à Bifrons, sous-zone à Sublevisoni, Khechem El Kelb, niveau KEK.9, PFT318 ; B, Homoeorhynchia batalleri (Dubar, 1931), Toarcien moyen, zone à Bifrons, sous-zone à Sublevisoni, Khechem El Kelb Est, niveau KEKE.10.1, PFT318. Échelle: 1 cm.

TABLEAU 1. - Dimensions et nombre de côtes des coquilles figurées de Quadratirhynchia vasconcellosi (Choffat in Dubar, 1931). Abréviations: $\mathbf{N}$, nombre de spécimens mesurés; L, I, E, longueur, largeur et épaisseur des coquilles (en $\mathrm{mm}) ; \mathbf{I} / \mathbf{L}, \mathbf{E} / \mathbf{L}$, largeur et épaisseur relatives; $\mathbf{h}$, hauteur du pli médian dorsal Is, largeur de l'uniplication frontale (mesurée à sa base); $\mathbf{h} / \mathbf{l s}, \mathbf{h} / \mathbf{L}$, hauteur du pli dorsal rapportée à sa largeur et à la longueur des coquilles; Nvd, nombre de côtes sur la valve dorsale; Nb, nombre de côtes sur le pli médian dorsal.

\begin{tabular}{lccccccccccc}
\hline Figs & $\mathbf{L}$ & $\mathbf{I}$ & $\mathbf{E}$ & $\mathbf{I} / \mathbf{L}$ & $\mathbf{E} / \mathbf{L}$ & $\mathbf{h}$ & $\mathbf{I s}$ & $\mathbf{h} / \mathbf{l s}$ & $\mathbf{h} / \mathbf{L}$ & $\mathbf{N v d}$ & $\mathbf{N b}$ \\
\hline 8A & 15,8 & 16,5 & 11,7 & 1,04 & 0,74 & 9,2 & 11,9 & 0,77 & 0,58 & 21 & 8 \\
8B & 21,8 & 19,8 & 18,2 & 0,91 & 0,83 & 13,9 & 12,7 & 1,09 & 0,64 & 23 & 7 \\
8C & 24,0 & 24,5 & 18,7 & 1,02 & 0,78 & 15,7 & 17,9 & 0,88 & 0,65 & 22 & 7 \\
9A & 15,5 & 17,3 & 11,7 & 1,12 & 0,75 & 11,0 & 11,7 & 0,94 & 0,71 & 14 & 5 \\
9B & 15,7 & 17,6 & 12,8 & 1,12 & 0,81 & 9,0 & 11,3 & 0,80 & 0,57 & 17 & 6 \\
9C & 22,0 & 23,8 & 17,3 & 1,08 & 0,79 & 14,3 & 13,8 & 1,04 & 0,65 & 25 & 8 \\
\hline
\end{tabular}

Espagne centrale et occidentale. Alt Empordà, Zone de Pedraforca, Zone sud-pyrénéenne, Sierras Marginales septentrionales et méridionales.

France : Provence méridionale, Pyrénées ariégeoises, du Comminges et de la Bigorre, Pyrénées basco-béarnaises. L'espèce est absente dans le Quercy.

\section{DESCRIPTION}

Espèce polymorphe de dimensions moyennes et de contour pentagonal-arrondi élargi transversalement. Les coquilles sont très renflées avec une vue latérale triangulaire. La valve dorsale est deux à quatre fois plus convexe que la valve ventrale plate ou faiblement convexe. Cette valve ventrale est creusée à l'avant d'un sinus large, plus ou moins profond mais bien délimité, auquel correspond un pli médian dorsal élevé et fortement projeté en avant. Moitié postérieure des valves toujours lisse. À l'avant, 6 à 20 côtes aiguës dont 2 à 8 sur le pli dorsal et 2 à 7 sur les parties latérales des coquilles.

Crochet court, subdressé à dressé. Foramen circulaire, punctiforme, submésothyride à mésothyride entre des crêtes latérales du crochet longues et bien marquées. Plaques deltidiales le plus souvent séparées.

Super-famille HEMITHIRIDOIDEA Rzhonsnitskaia, 1956

Famille CyClOTHYRIDIDAE Makridin, 1955

Sous-famille CARDINIRHYNCHIINAE Makridin, 1964

Genre Parvirhynchia Buckman, 1917

ESPÈCE TYPE. - Rhynchonella parvula Deslongchamps, 1862 par désignation originale (Buckman 1917: 56).

\section{Parvirhynchia parvula (Deslongchamps, 1862)}

Rhynchonella parvula Deslongchamps, 1862: 29, pl. 5, figs 5, 6 .

Parvirhynchia parvula - Alméras \& Lathuilière 1984 : 789, pl. 1, figs 1-29, pl. 2, figs 1-9, avec la synonymie. - Alméras \& Fauré 2008: 630 , pl. 4 , figs 14,15 , avec la synonymie.

Matériel eXaminé. - Khechem El Kelb Est, niveau KEKE.14 (1 exemplaire) ; Châabet El Attaris, niveau CHA.9 (1 exemplaire).

ÂGE ET RÉPARTITION. — Voir Alméras \& Lathuilière (1984: 813). France : Bajocien inférieur, zone à Humphriesianum du Mâconnais, de la Nièvre, Côte d'Or, Franche-Comté, Jura, Ile Crémieu (Jura du Sud) et Mont d'Or lyonnais. En outre, Provence méridionale (Bajocien inférieur, zone à Sauzei).

Haut-Atlas central, au Maroc et Monts de Rhar Roubane, en Algérie occidentale: Bajocien inférieur, zones à Propinquans et à Humphriesianum.

\section{DESCRIPTION}

Deux spécimens de 11,5 et 13,5 mm de long, dans un état de conservation insuffisant pour être figurés. La morphologie et la costulation du plus petit correspondent à celles de la coquille 
TABLEAU 2. - Valeurs moyennes et intervalles de variation des dimensions et du nombre de côtes chez diverses populations de Quadratirhynchia vasconcellosi (Choffat in Dubar, 1931). Abréviations: 1, Tunisie (Axe Nord-Sud); 2, Algérie occidentale (Ouarsenis, Monts de Saïda et Takhmaret) (données de Alméras et al. 2007a: tableau 27); 3, rampe carbonatée de Tomar, au Portugal (données de Alméras et al. 1996: tableau 4); 4, Pyrénées (Pyrénées ariégeoises, du Comminges et de la Bigorre et en Espagne: Zone de Pedraforca, Zone sud-pyrénéenne, Sierras Marginales septentrionales et méridionales; données de Alméras \& Fauré 2000: tableau 51).

\begin{tabular}{|c|c|c|c|c|c|c|c|c|c|}
\hline & $\mathbf{N}$ & $\mathbf{L}$ & & \multicolumn{2}{|c|}{ I } & \multicolumn{2}{|r|}{$\mathbf{E}$} & I/L & E/L \\
\hline 1 & 40 & \multicolumn{2}{|c|}{$16,7(11,7-24,0)$} & \multicolumn{2}{|c|}{$17,9(12,0-24,5)$} & \multicolumn{2}{|c|}{$13,8(8,0-18,7)$} & $1,07(0,91-1,23)$ & $0,83(0,68-0,96)$ \\
\hline 2 & 28 & \multicolumn{2}{|c|}{$19,5(12,0-24,2)$} & \multicolumn{2}{|c|}{$20,6(14,2-24,7)$} & \multicolumn{2}{|c|}{$16,3(8,6-21,2)$} & $1,06(0,92-1,17)$ & $0,83(0,72-0,99)$ \\
\hline 3 & 23 & \multicolumn{2}{|c|}{$20,3(15,7-27,0)$} & \multicolumn{2}{|c|}{$22,4(18,9-27,0)$} & \multicolumn{2}{|c|}{$17,6(14,3-23,6)$} & $1,12(1,01-1,37)$ & $0,88(0,76-1,05)$ \\
\hline 4 & 59 & \multicolumn{2}{|c|}{$19,3(11,0-24,6)$} & \multicolumn{2}{|c|}{$21,1(11,7-26,5)$} & \multicolumn{2}{|c|}{$16,6(5,8-21,4)$} & $1,09(0,96-1,24)$ & $0,85(0,53-1,08)$ \\
\hline & \multicolumn{2}{|r|}{$\mathbf{h}$} & \multicolumn{2}{|c|}{ Is } & \multicolumn{2}{|c|}{$h / l s$} & h/L & Nvd & $\mathrm{Nb}$ \\
\hline 1 & \multicolumn{2}{|c|}{$11,3(6,0-15,7)$} & \multicolumn{2}{|c|}{$11,5(7,0-17,9)$} & \multicolumn{2}{|c|}{$0,99(0,72-1,14)$} & $0,68(0,51-0,81)$ & $18,2(12-25)$ & $5,8(3-8)$ \\
\hline 2 & \multicolumn{2}{|c|}{$10,8(6,4-14,7)$} & \multicolumn{2}{|c|}{$13,0(7,9-17,0)$} & \multicolumn{2}{|c|}{$0,84(0,55-1,14)$} & $0,55(0,39-0,75)$ & $13,6(8-20)$ & $4,7(2-7)$ \\
\hline 3 & \multicolumn{2}{|c|}{$14,3(10,0-20,0)$} & \multicolumn{2}{|c|}{$15,2(11,8-20,5)$} & & $0,72(0,51-0,95)$ & $14,9(9-21)$ & $5,6(4-8)$ \\
\hline 4 & \multicolumn{2}{|c|}{$14,4(3,2-20,7)$} & \multicolumn{2}{|c|}{$13,8(6,2-18,8)$} & \multicolumn{2}{|c|}{$1,03(0,40-1,55)$} & $0,73(0,29-1,02)$ & $14,4(11-19)$ & $5,6(3-8)$ \\
\hline
\end{tabular}

du Haut-Atlas central (flanc sud de la vallée du Rhéris) figurée par Alméras \& Fauré (2008: pl. 4, fig. 15). Par la densité de sa costulation, le deuxième se rapproche (avec toutefois une épaisseur un peu plus forte) des exemplaires du Mâconnais figurés par Alméras \& Lathuilière (1984: pl. 1, figs 27, 29).

Famille TETRARHYNCHIIDAE Ager, 1965

Sous-famille TETRARHYNCHIINAE Ager, 1965

Genre Quadratirhynchia Buckman, 1917

ESPÈCE TYPE. — Quadratirhynchia quadrata Buckman, 1917 par désignation originale (Buckman 1917: 42).

Quadratirhynchia vasconcellosi (Choffat in Dubar, 1931) (Figs 8A-C; 9A-C; Tableaux 1, 2)

Rhynchonella vasconcellosi Choffat in Dubar, 1931: 22, pl. 1, figs 9, 10.

Quadratirhynchia vasconcellosi - Alméras et al. 1996: 149, pl. 2, figs 1-6, avec la synonymie; 1997: 114, fig. 2(16, 17); 2007a: 83, pl. 5, figs 13-16; 2010a: 36, pl. 2, fig. 13. - Alméras \& Fauré 2000: 166, pl. 17, figs 1-8. — Fauré et al. 2004: 58, pl. 3, figs 12, 13.

Choffatirhynchia vasconcellosi-García Joral \& Goy 2004: 242, pl. 1, figs 1-4. - García Joral et al. 2011: fig. 5(6).

Matériel eXAminé. - Khechem El Kelb, niveaux KEK.2(2010) (17 exemplaires), KEK.2(2011) (7 exemplaires), KEK.3(2011) (4 exemplaires), KEK.5(2011) (2 exemplaires), KEK.6(2010) (4 exemplaires), KEK.8(2010) (2 exemplaires), KEK.10(2010) (1 exemplaire), KEK.11(2010) (1 exemplaire); Khechem El Kelb Est, niveaux KEKE.2 (2 exemplaires), KEKE.10 (2 exemplaires).

Châabet El Attaris, niveaux CHA.1 (5 exemplaires), CHA.3 (2 exemplaires) et, hors place, CHA.0 (2 exemplaires), CHA.00 (4 exemplaires). Soit au total, 55 spécimens dont 6 figurés (Figs 8A-C; 9A-C) et 40 mesurés (Tableau 2).

ÂGE ET RÉPARTITION. - Toarcien inférieur, zone à Serpentinum (= zone à Levisoni en domaine sud-téthysien) et Toarcien moyen, zone à Bifrons, sous-zone à Sublevisoni (seulement).

Algérie occidentale (Ouarsenis, Monts des Traras, de Rhar Roubane et de Saïda, secteur de Takhmaret). Maroc (Moyen-Atlas, Haut-Atlas central). Portugal (Sous-bassin nord-lusitanien). Espagne (Zones sud-pyrénée- nne et de Pedraforca, Catalogne, Sierras Marginales septentrionales et méridionales, Sierras Marginales occidentales du Haut-Aragon, Cordillère Ibérique). France (Provence méridionale, Pyrénées ariégeoises, du Comminges et de la Bigorre, Bordure sud du Massif Armoricain. Espèce absente dans le Quercy).

Dimensions. - Voir Tableau 1 (dimensions et nombre de côtes des coquilles figurées) et Tableau 2 (valeurs moyennes et intervalles de variation des dimensions et du nombre de côtes).

\section{DESCRIPTION}

Coquilles uniplissées de dimensions moyennes (Longueur 12 à $24 \mathrm{~mm}$; Tableau 2). Par ses dimensions et sa morphologie générale, Quadratirhynchia vasconcellosi peut être confondue avec Homoeorhynchia batalleri. Elle s'en différencie essentiellement par sa costulation recouvrant entièrement la surface des valves ou bien apparaissant à proximité du sommet du crochet et de l'umbo dorsal. Cette costulation consiste en 12 à 25 côtes de type tetrahedra ou quadrata selon leur densité ; 3 à 8 d'entre elles ornent le pli médian dorsal. L'uniplication frontale est nettement moins élevée chez les plus grandes coquilles de $Q$. vasconcellosi alors que les coquilles de même taille de $H$. batalleri montrent un fort relèvement du pli médian dorsal très projeté en avant. En outre, la partie postérieure de la valve ventrale, aplatie chez $H$. batalleri, est régulièrement convexe en tous sens chez Q. vasconcellosi. Chez cette espèce, l'uniplication frontale est aplatie en son sommet, ce qui crée un sinus ventral quadratique mais mal délimité, convexe ou peu creusé, auquel correspond un pli médian dorsal. À l'exception des spécimens adultes (Figs 8C; 9B, C), ce pli dorsal régulièrement arrondi se raccorde progressivement aux parties latérales des coquilles. L'uniplication frontale peut présenter quelques asymétries (quatre exemplaires sur 36).

Le crochet le plus souvent dressé surplombe l'umbo dorsal. Il se recourbe avec l'âge, se rapprochant alors de ce dernier. Toutefois, huit crochets subdressés ou subdressés à dressés ont pu être dénombrés. Foramen presque toujours circulaire, submésothyride entre de courtes crêtes latérales arrondies du crochet, ces dernières pouvant même faire défaut. L'area cardinale, large mais basse, laisse apercevoir des plaques deltidiales séparées. Le spécimen de la Figure 9C montre un crochet 

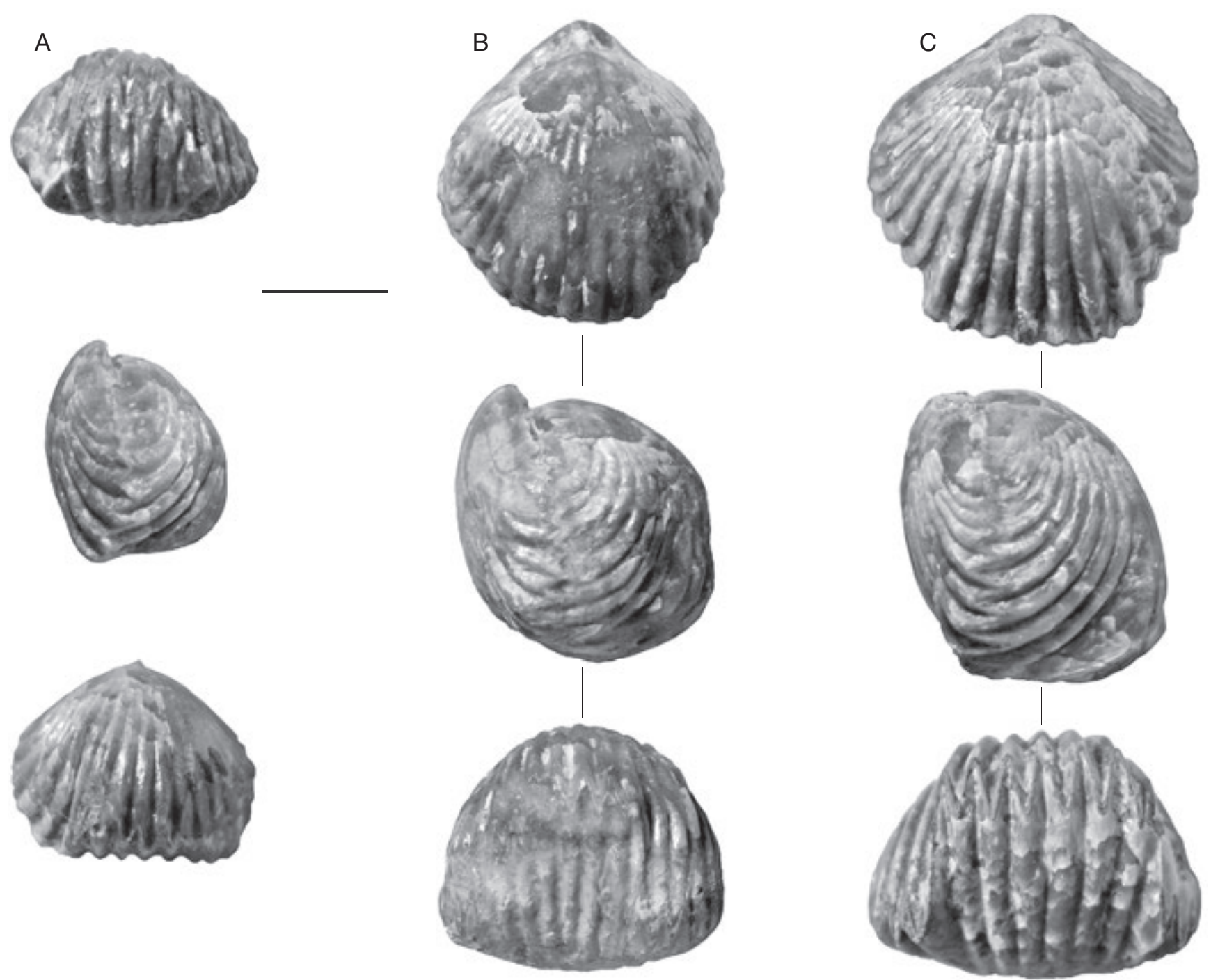

FIG. 8. - A-C, Quadratirhynchia vasconcellosi (Choffat in Dubar, 1931), Toarcien inférieur, zone à Serpentinum. Khechem El Kelb : A-C, trois spécimens de taille croissante (niveau KEK.2), PFT320 (A), PFT321 (B), PFT322 (C). Mensurations des exemplaires figurés : voir Tableau 1. Échelle : $1 \mathrm{~cm}$.

dressé, bien élevé au-dessus de l'umbo dorsal. Les crêtes latérales de son crochet sont bien marquées et les plaques deltidiales sont réunies par leur base. Il s'agit aussi de la coquille la plus densément costée de l'échantillon examiné.

\section{REMARQUE}

Les spécimens tunisiens possèdent des dimensions plus petites qu'en Algérie occidentale, sur la rampe carbonatée de Tomar, au Portugal, ou dans les Pyrénées (Tabl. 2). Cette différence s'explique par la rareté des coquilles adultes collectées. Par contre, on rencontre fréquemment des spécimens miniaturisés précocement uniplissés (Fig. 9A), c'est-à-dire des individus reproduisant à des tailles plus petites la morphologie (et particulièrement l'uniplication frontale) des spécimens adultes ou sub-adultes. La costulation est parfois plus dense sur les spécimens tunisiens : on observe sensiblement les mêmes valeurs moyennes de Nvd, mais la limite supérieure de l'intervalle de variation est supérieure en Tunisie ( 25 côtes contre 19 à 21 ; voir Tableau 2).

\section{Sous-famille GIBBIRHYNCHIINAE \\ Manceñido \& Owen, 2002}

Genre Burmirhynchia Buckman, 1917

ESPĖCE TYPE. - Burmirhynchia gutta Buckman, 1917 par désignation originale (Buckman 1917: 49).

\section{Burmirhynchia termierae}

Rousselle, 1965 pars, sensu Alméras \& Sadki (1992)

Burmirhynchia? termierae Rousselle, 1965: 37 (pars).

Burmirhynchia termierae (pars), sensu Alméras \& Sadki 1992: 169, fig. 4-5; pl. 1, fig. 3-17. - Alméras \& Fauré 2008: 605, pl. 1, figs 15-20 et pl. 2, fig. 1, avec la synonymie. - Alméras et al. 2010b: 28, pl. 2, figs 5-14.

Matériel eXaminé. — Khechem El Kelb, niveau KEK.14 : 1 spécimen. 

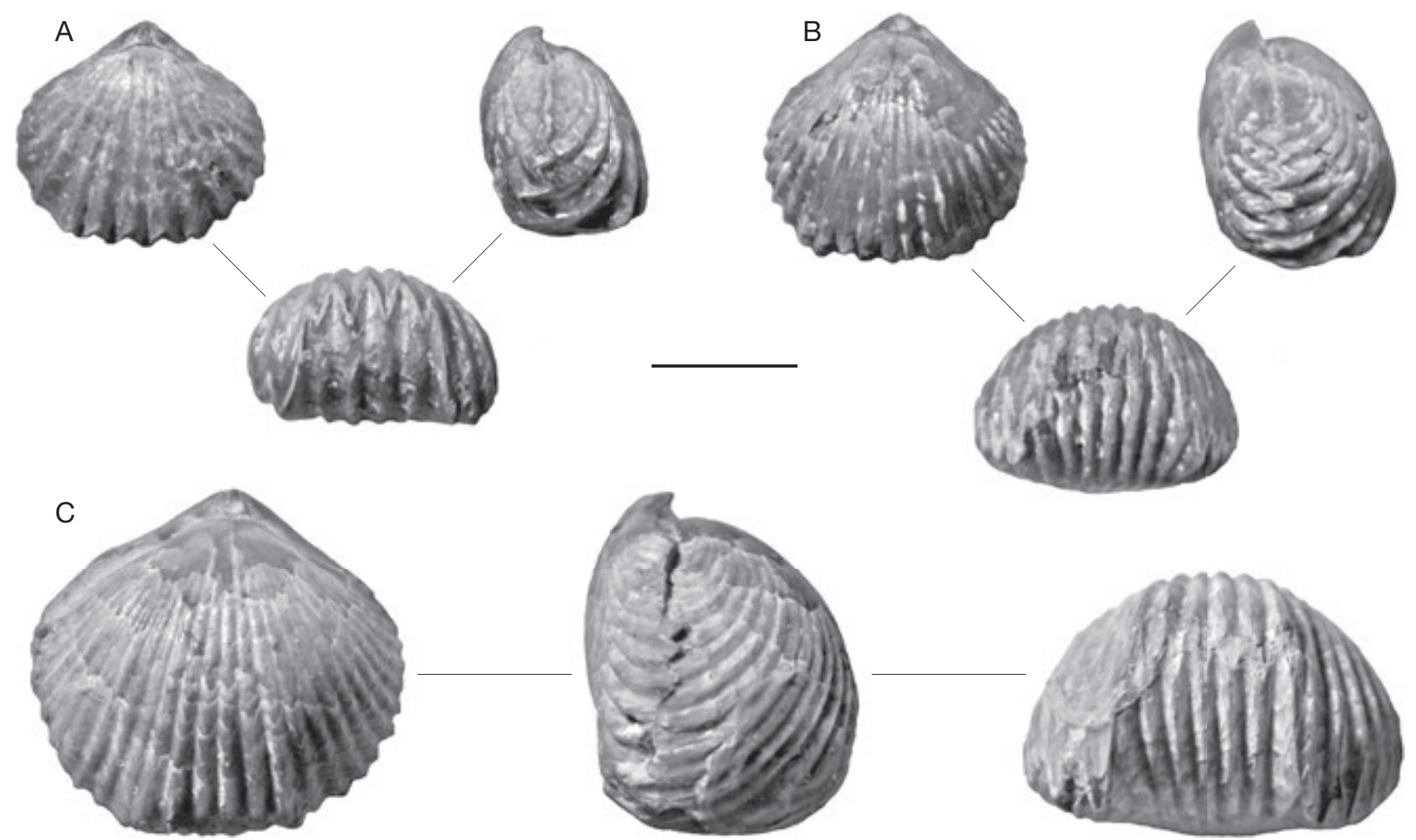

FIG. 9. - A-C, Quadratirhynchia vasconcellosi (Choffat in Dubar, 1931), Toarcien inférieur, zone à Serpentinum, Khechem El Kelb ; A, spécimen miniaturisé précocement uniplissé (niveau KEK.2), PFT323 ; B, C, variabilité de la costulation, avec (C) coquille la plus densément costée (Nvd = 25$)$ (niveau KEK.3), PFT324 (B), PFT325 (C). Mensurations des exemplaires figurés : voir Tableau 1. Échelle : $1 \mathrm{~cm}$.

ÂGE ET RÉPARTITION. — Bajocien inférieur, zone à Humphriesianum et Bajocien supérieur, zone à Niortense (= zone à Runcinatum). Maroc (Moyen-Atlas, Haut-Atlas central) et Algérie occidentale (Monts des Ksour occidentaux). Moyen-Orient : Sinaï, Negev, Arabie Saoudite, Jordanie.

\section{REMARQUE}

Ce spécimen est de dimensions et de morphologie comparables à celles de la coquille du Haut-Atlas central (Aïn Outtat) figurée par Alméras \& Fauré (2008: pl. 1, fig. 16).

\section{?Burmirhynchia athiensis Rousselle, 1965}

Burmirhynchia? termierae Rousselle, 1965: 37 (pars).

Burmirhynchia athiensis - Alméras \& Fauré 2008: 609, pl. 2, figs 5-13, avec la synonymie. - Alméras et al. 2010b: 32, pl. 3, figs 1-6, avec la synonymie.

Matériel EXAminÉ. — Khechem El Kelb, niveau KEK.25 : 2 spécimens.

ÂGe et RÉPARtition. - Bajocien supérieur, zone à Parkinsoni et Bathonien inférieur, zone à Zigzag.

Répartition: voir Alméras et al. 2010b: 35.

\section{REMARQUE}

Ces deux spécimens mal conservés sont comparables aux deux coquilles d'Arabie Saoudite centrale figurées par Alméras et al. (2010b: pl. 3, figs 4, 5). Ils ont été collectés avec Sphenorhynchia zraigensis.
Ordre TEREBRATULIDA Waagen, 1883

Sous-ordre TEREBRATULIDINA Waagen, 1883 Super-famille LOBOIDOTHYRIDOIDEA Makridin, 1964

Famille LOBOIDOTHYRIDIDAE Makridin, 1964

Sous-famille LOBOIDOTHYRIDINAE Makridin, 1964

Genre Ptyctothyris Buckman, 1917

ESPÈCE TYPE. - Terebratula stephani Davidson, 1877 par désignation originale (Buckman 1917: 101).

\section{?Ptyctothyris biplicata (Rousselle, 1965)}

Cererithyris linguifera biplicata Rousselle, 1965: 75, pl. 14, figs 4-12, pl. 15, figs 1-6 (pars).

Ptyctothyris biplicata-Alméras \& Fauré 2008: 687, pl. 11, figs 1-4, avec la synonymie.

Matériel eXAminé. — Khechem El Kelb, niveau KEK.25 : 2 spécimens partiellement érodés comparables à la coquille des Monts des Ksour occidentaux (Algérie occidentale) illustrée par Alméras \& Fauré (2008: pl. 11, fig. 1).

ÂGE ET RÉPARTITION. - Bathonien inférieur, depuis la sous-zone à Macrescens (zone à Zigzag) jusqu'à la sous-zone à Tenuiplicatus (zone à Aurigerus). Maroc : Moyen-Atlas, Hauts-Plateaux, HautAtlas oriental (Jbel Mechkakour). Algérie occidentale : Monts des Ksour. 

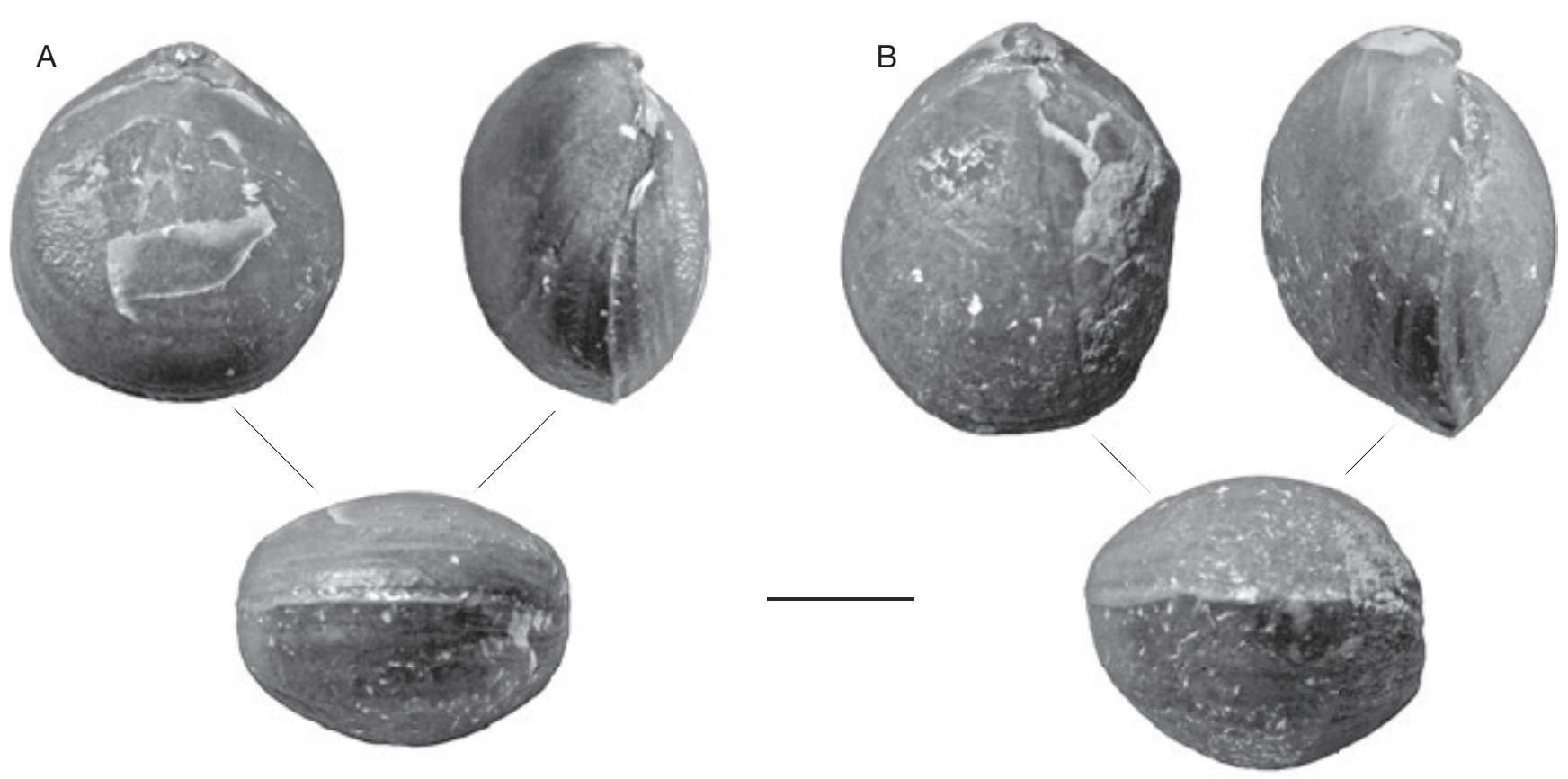

FIG. 10. - A, B, Sphaeroidothyris lenthayensis (Richardson \& Walker, 1907), Bathonien inférieur, zone à Zigzag, sous-zone à Parvum, Châabet El Attaris, niveaux CHA.10, PFT327 (B) et CHA.12, PFT326 (A). Échelle : $1 \mathrm{~cm}$.

Genre Sphaeroidothyris Buckman, 1917

ESPÈCE TYPE. - Sphaeroidothyris globisphaeroidalis Buckman, 1917 par désignation originale (Buckman 1917: 115).

Sphaeroidothyris lenthayensis (Richardson \& Walker, 1907) (Fig. 10A, B)

Terebratula lenthayensis Richardson \& Walker, 1907: 432, pl. 29, fig. 2.

Sphaeroidothyris lenthayensis-Muir-Wood 1936: 75, pl. 4, fig. 9. Alméras 1971: 287, pl. 44, figs 8-11. — Alméras \& Moulan 1988: 179, pl. 12, fig. 2. - Alméras \& Guégan 2009: 22, pl. 3, fig. 3.

MATÉRIEl EXAMiné. - Châabet El Attaris, niveaux CHA.10 (1 exemplaire), CHA.11 (6 exemplaires), CHA.12 (2 exemplaires).

ÂGe ET RÉpARtition. - Angleterre : Lower Fuller's Earth, "The Scroff " (= partie supérieure du Bathonien inférieur) du Dorset et du Somerset.

France : Bathonien inférieur, zone à Zigzag de Provence méridionale (sous-zone à Macrescens), du Jura méridional et de Normandie.

Dimensions. - Sept exemplaires mesurables: PFT326 (Fig. 10A), longueur 24,7 mm, largeur 22,6 mm, épaisseur 17,8 mm ; PFT327 (Fig. 10B), longueur $28 \mathrm{~mm}$, largeur 22,6 mm, épaisseur $20 \mathrm{~mm}$.

\section{DESCRIPTION}

Coquilles de longueur comprise entre 19,5 et $28 \mathrm{~mm}$, de contour circulaire aux stades jeunes du développement, s'allongeant légèrement chez les coquilles adultes $(\mathrm{l} / \mathrm{L}=0,95$ à $0,81)$. Valves fortement renflées $(\mathrm{E} / \mathrm{L}$ moyen $=0,70)$. Amorce d'uniplication frontale large et tardive. Commissures latérales très peu curvilignes. Ni pli, ni sillons à la surface des valves. Crochet massif, large, non crêté, court, recourbé et en contact avec l'umbo dorsal. Petit foramen circulaire.

\section{REMARQUE}

La coquille de la Figure 10B est identique à celle de Provence méridionale (environs de Cuers) figurée par Alméras \& Moulan (1988: pl. 12, fig. 2).

Sphaeroidothyris elmii Alméras \& Moulan, 1988

(Fig. 11A-C)

Sphaeroidothyris elmii Alméras \& Moulan, 1988: 182, pl. 11, figs 11-19. - Alméras \& Guégan 2009: 22, pl. 3, fig. 4.

Matériel eXAminé. - Khechem El Kelb, niveaux KEK.32 (8 exemplaires), KEK.33 (10 exemplaires), KEK.35 (5 exemplaires) et KEK.36 (4 exemplaires).

Dimensions. - PFT328 (Fig. 11A), longueur 21,9 mm, largeur 18,9 mm, épaisseur 15,7 mm; PFT329 (Fig. 11B), longueur 26,3 $\mathrm{mm}$, largeur 20,3 mm, épaisseur 20,7 mm; PFT330 (Fig. 11C), longueur ?27 mm, largeur 20,6 mm, épaisseur 24,8 mm.

ÂGE ET RÉPARTITION. — Provence méridionale: Bathonien moyen, zone à Bremeri ou Bathonien supérieur, zone à Retrocostatum, sous-zone à Blanazense. Normandie; Bathonien supérieur, zoneà Hodsoni (= équivalente en province subboréale de l'âge donné en Provence méridionale).

\section{DESCRIPTION}

Coquilles longues de 21,7 à 32,5 mm. De largeur variable $(1 / \mathrm{L}=0,97$ à 0,81$)$, elles sont subsphériques dans leur forme moyenne (valeurs moyennes de $1 / \mathrm{L}$ et E/L calculées sur 18 exemplaires mesurés $=$ respectivement 0,86 et 0,87$)$. Le caractère principal de l'espèce réside dans la forte équiconvexité de ses valves, presque hémisphériques, qui, de ce fait, se réunissent toujours, à l'âge adulte, sous un angle obtus. Commissure 

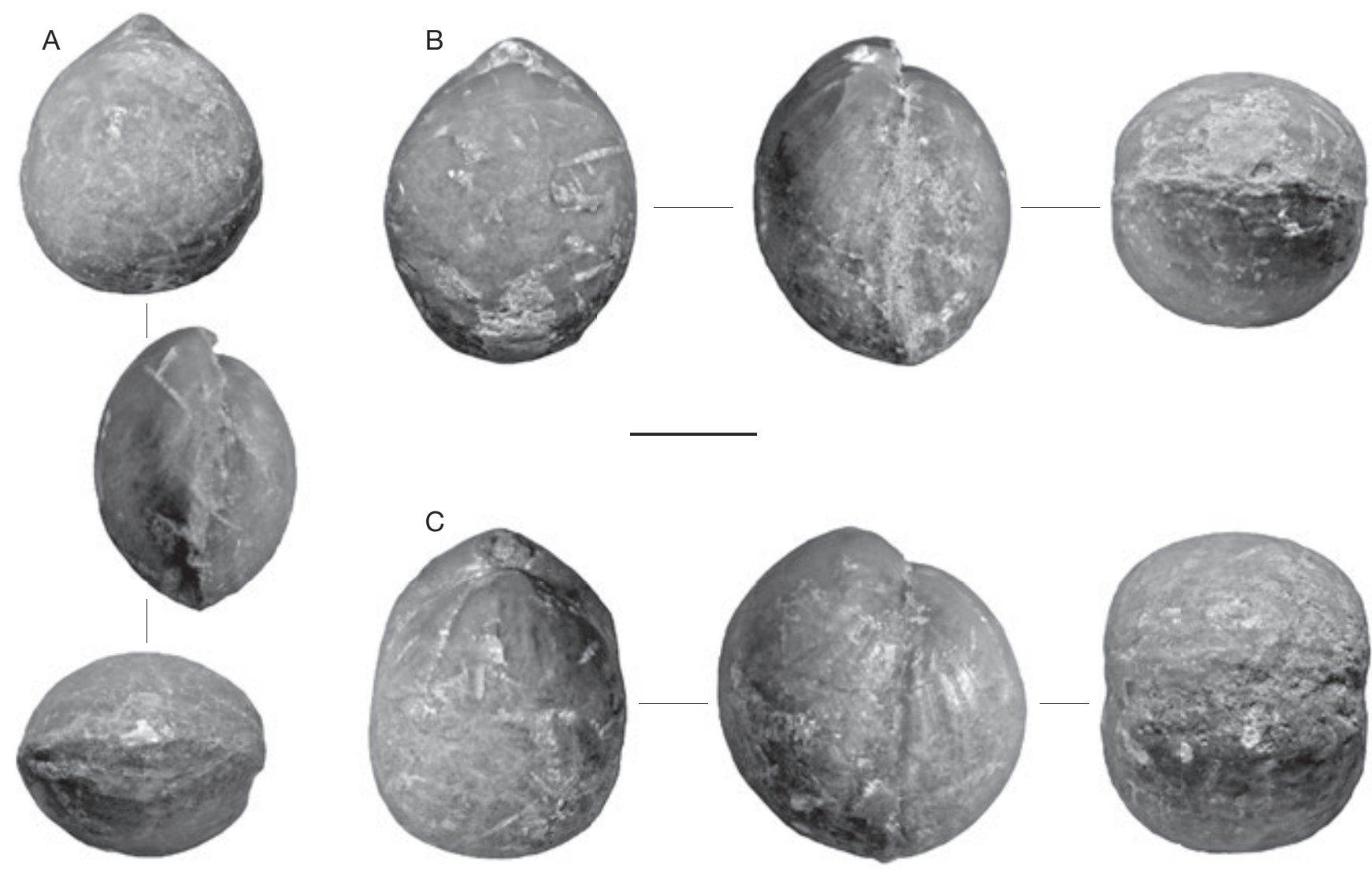

FIG. 11. - A-C, Sphaeroidothyris elmii Alméras \& Moulan, 1988, Bathonien moyen, zone à Bremeri, Khechem El Kelb : A, niveau KEK.33, PFT328 ; B, niveau KEK.36, PFT329 ; C, niveau KEK.35, PFT330. Morphogenèse illustrée par trois spécimens de taille croissante. Échelle : $1 \mathrm{~cm}$.

frontale et commissures latérales situées dans un même plan. Crochet massif, non crêté, dressé à légèrement recourbé et en contact avec l'umbo dorsal. Petit foramen circulaire, permésothyride, non labié. Symphytium non exposé.

Famille LISSAJOUSITHYRIDIDAE Cooper, 1983 Sous-famille LisSAJOUSITHYRIDINAE Cooper, 1983

\section{Genre Monsardithyris Alméras, 1971}

ESPÈCE TYPE. - Terebratula ventricosa Zieten, 1830 par désignation originale (Alméras 1971: 298).

\section{Monsardithyris sp.}

Matériel eXAminé. - Khechem El Kelb Est, niveau KEKE.14 (1 exemplaire). Châabet El Attaris, niveau CHA.9 (1 exemplaire).

Famille LOBOTHYRIDIDAE Makridin, 1964 Sous-famille LOBOTHYRIDINAE Makridin, 1964

Genre Telothyris Alméras \& Moulan, 1982

ESPÈCE TYPE. - Terebratula jauberti var. pyrenaica Dubar, 1931 par désignation originale (Alméras \& Moulan 1982: 136).
Telothyris jauberti (Deslongchamps, 1863) (Tableaux 3, 4 ; Fig. 12A-F)

Terebratula jauberti Deslongchamps, 1863 : 271, pl. 11, fig. 1; 1862-1885: 176, pl. 46, figs 1-4, pl. 48, fig. 1. - Delance 1969: 33, pl. A, figs 9, 10. — Goy 1974: 747, pl. 103, figs 1-3.

Telothyris jauberti-Alméras \& Moulan 1982: 148, pl. 10, figs 1-12, pl. 11, figs 1-13. - Alméras 1996b: 88, pl. 5, figs 1-3. — Alméras et al. 1996: 155, pl. 3, figs 1-12; 1997: 114, fig. 2 (7-13); 2007a: 96, pl. 7, figs 11-14, pl. 8, figs 1-4; 2010a: 50, fig. h.t. 15, pl. 3, figs 10, 11. - Alméras \& Fauré 2000: 95, pl. 10, figs 1-10.

Matériel eXAminé. - Khechem El Kelb, niveaux KEK.2(2010) (142 exemplaires), KEK.2(2011) (26 exemplaires), KEK.3(2011) (29 exemplaires), KEK.4(2011) (2 exemplaires), KEK.5(2011) (1 exemplaire), KEK.6(2010) (8 exemplaires), KEK.6(2011) (4 exemplaires), KEK.7(2011) (7 exemplaires), KEK.8(2010) (2 exemplaires), KEK.10(2010) (2 exemplaires) ; Khechem El Kelb Est niveaux KEKE. 2 (7 exemplaires), KEKE. 8 (2 exemplaires), KEKE.10 (4 exemplaires). Châabet El Attaris, niveaux CHA.1 (47 exemplaires), CHA.3 (1 exemplaire), CHA.4 (2 exemplaires) et, hors place, niveau CHA.00 (un exemplaire) (soit au total, 287 exemplaires dont 142 ont été mesurés ; voir Tableau 4).

ÂGE ET RÉPARTITION. — Espèce-indice de la zone à Homoeorhynchia batalleri et Telothyris jauberti. Toarcien inférieur, zone à Serpentinum et Toarcien moyen, zone à Bifrons, sous-zone à Sublevisoni.

Plates-formes de l'Europe moyenne : Sarthe, Quercy (rare), Éperon lyonnais (La Verpillière). 
TABlEAU 3. - Dimensions des coquilles figurées de Telothyris jauberti (Deslongchamps,1863)

\begin{tabular}{lccccc}
\hline Figures & $\mathbf{L}$ & $\mathbf{I}$ & $\mathbf{E}$ & $\mathbf{I} \mathbf{L}$ & $\mathbf{E} / \mathbf{L}$ \\
\hline $12 \mathrm{~A}$ & 20,0 & 18,9 & 10,9 & 0,94 & 0,54 \\
$12 \mathrm{~B}$ & 24,8 & 22,5 & 13,8 & 0,91 & 0,56 \\
$12 \mathrm{C}$ & 23,8 & 20,3 & 14,7 & 0,85 & 0,62 \\
$12 \mathrm{D}$ & 21,6 & 21,6 & 11,5 & 1,00 & 0,53 \\
$12 \mathrm{E}$ & 29,9 & 29,4 & 16,2 & 0,98 & 0,54 \\
$12 \mathrm{~F}$ & 31,3 & 25,0 & 18,0 & 0,80 & 0,57 \\
\hline
\end{tabular}

Domaine nord-téthysien occidental : France (Provence méridionale, Pyrénées ariégeoises et basco-béarnaises, Comminges et Bigorre), Espagne (Aragon, Catalogne, provinces de Teruel et Lérida, Alt Empordà, Pedraforca, Zone sud-pyrénéenne, Sierras Marginales septentrionales et méridionales, Cordillère Ibérique), Portugal (Sud de Coimbra et rampe carbonatée de Tomar).

Domaine sud-téthysien occidental : Maroc (Moyen-Atlas, HautAtlas central), Algérie occidentale (Ouarsenis, Monts des Traras, de Rhar Roubane, de Saïda et secteur de Takhmaret), Tunisie (Axe Nord-Sud).

DimENSIONS. - Tableau 3: dimensions des coquilles figurées; Tableau 4 : valeurs moyennes et intervalles de variation des dimensions.

\section{DESCRIPTION}

Espèce de taille moyenne à grande, avec des coquilles dont la longueur varie entre 11,8 et $32 \mathrm{~mm}$, les spécimens (Fig. 12EF) se situant parmi ceux possédant la plus grande longueur. Si les stades juvéniles sont subcirculaires ou légèrement ovales (Fig. 12A, D), la croissance, loin d'être toujours isomorphe, conduit à des adultes de contour arrondi (Fig. 12E) comme à des adultes de contour ovale, parfois même très allongé (Fig. 12B, C). Épaisseur faible à modérée, augmentant au cours de la croissance, le rapport $\mathrm{E} / \mathrm{L}$ variant entre 0,46 et 0,63 (Tabl. 4). Epaisseur maximale des valves située en leur milieu. Le plissement frontal de Telothyris jauberti constitue l'un des caractères les plus variables de sa morphologie. L'ontogenèse frontale passe par les stades rectimarginé (le plus fréquemment représenté dans nos échantillons tunisiens), puis planoplissé (29 exemplaires sur les 142 mesurés), ou sulciplissé (16 exemplaires avec sulciplication élevée). Ce plissement n'affecte pas le relief antérieur de la valve ventrale convexe en tous sens. Sur les spécimens sulciplissés, il existe un sinus médian localisé sur l'avant de la valve dorsale. Les commissures latérales sont rectilignes. Elles sont légèrement curvilignes sur les plus grands exemplaires, où elles se relèvent à peine et régulièrement à l'approche du front. Latéralement, les valves se réunissent sous un angle aigu, parfois droit, donnant ainsi des commissures tranchantes [différence avec Telothyris pyrenaica (Dubar) de plus petites dimensions].

En raison du grand nombre de coquilles rectimarginées, les dimensions de nos échantillons tunisiens sont plus petites que celles observées en Provence méridionale où la plus grande taille peut atteindre $44 \mathrm{~mm}$ (comparer les dimensions sur les lignes 4 et 5 du Tabl. 4 avec celles de la ligne 6 du même tableau ; voir aussi Alméras \& Moulan [1982, figs 49, 50] et Alméras et al. [2010a: fig. h.t. 15]). Ces plus petites dimensions de Telothyris jauberti en Tunisie se retrouvent sur la
Bordure sud du Massif Armoricain où les sujets rectimarginés sont également majoritaires (comparer les lignes 4 et 7 du Tableau 4). Rappelons ici que Telothyris jauberti se situe dans les mêmes niveaux que Quadratirhynchia vasconcellosi dont les exemplaires tunisiens (rareté des coquilles adultes, nombreux spécimens miniaturisés précocement uniplissés) possèdent également des dimensions plus petites qu'en Algérie occidentale, sur la rampe carbonatée de Tomar ou dans les Pyrénées.

Crochet petit à moyen (au vu de la taille des coquilles), court et large, dressé ou recourbé. Le foramen, de dimensions modestes, est circulaire, mésothyride ou permésothyride entre des crêtes latérales du crochet marquées, plus ou moins aiguës, généralement assez longues. Symphytium non ou peu exposé.

\section{Sous-famille LOPHROTHYRIDINAE Cooper, 1983}

$$
\text { Genre Aromasithyris Alméras, } 1971
$$

ESPÈCE TYPE. - Aromasithyris almerasi Boullier, 1976 pour Terebratula balinensis (non Szajnocha, 1879 in Alméras 1971: pl. 190, fig. 4).

\section{Aromasithyris dreyfussi Boullier, 1976}

Aromasithyris dreyfussi Boullier, 1976: 181, pl. 5, figs 6-11.

Matériel eXAminé. — Khechem El Kelb, niveau KEK.38: 1 exemplaire à crochet non conservé.

ÂGe et répARTITION. - France (Jura central, Collines préjurassiennes, Plateaux de Haute-Saône et Bourgogne). Callovien supérieur, zones à Athleta et à Lamberti.

Genre Tubithyris Buckman, 1917

ESPÈCE TYPE. - Terebratula wrighti Davidson, 1854 par désignation originale (Buckman 1917: 115).

Tubithyris chouberti Rousselle, 1965

(Fig. 13A)

Tubithyris globata var. chouberti Rousselle, 1965: 109, pl. 9, figs 10, 12, pl. 10, figs 1-12, pl. 11, figs 1-14, pl. 12, figs 1,2 .

Tubithyris chouberti-Alméras $1987: 183$, pl. 5, figs 3-9. — Ahmad 2000: 302, fig. 1 (1); 2003: fig. 5 (7-9). — Alméras \& Fauré 2008: 700. - Alméras et al. 2010b: 73, pl. 11, figs 1-12.

MATÉRIEL eXAminé. - Khechem El Kelb Est, niveau KEKE.14: 6 exemplaires dont celui représenté en Figure 13A.

ÂGE ET RÉPARTITION. - Bajocien inférieur, zone à Humphriesianum et Bajocien supérieur, zone à Niortense (= zone à Runcinatum de la bioprovince arabique).

Maroc (Moyen-Atlas, Hauts-Plateaux, Haut-Atlas central et oriental, Rides Sud-Rifaines), Tunisie (Axe Nord-Sud), Arabie Saoudite centrale, Jordanie.

Dimensions. - PFT337, longueur 26,3 mm, largeur 20,8 mm, épaisseur 18,5 mm (Fig. 13A). 

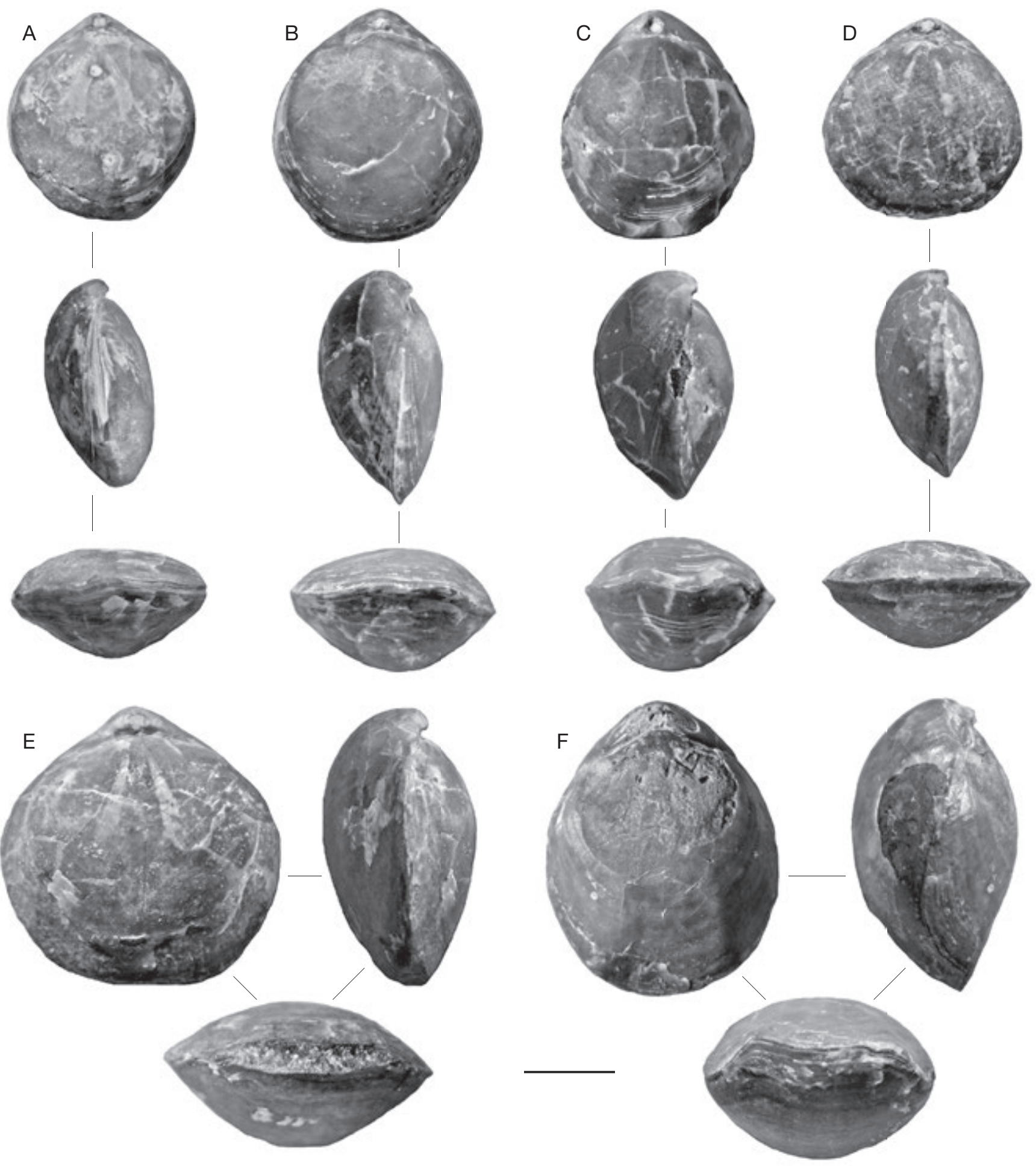

FIG. 12. - Telothyris jauberti (Deslongchamps, 1863), Toarcien inférieur, zone à Serpentinum : A-C, Khechem El Kelb, niveau KEK.2, PFT331 (A), PFT332 (B), PFT333 (C) ; D-F, Châabet El Attaris, niveau CHA.1, PFT334 (D), PFT335 (E), PFT336 (F) ; A, B, deux coquilles de taille croissante, avec un contour ovale allongé ; $\mathbf{C}$, coquille ovale allongée avec sulciplication élevée; $\mathbf{D}$, E, deux coquilles de taille croissante, avec un contour circulaire ; $\mathbf{F}$, coquille ovale allongée planoplissée. Mensurations des exemplaires figurés : voir Tableau 3. Échelle : $1 \mathrm{~cm}$.

\section{DESCRIPTION}

La coquille de la Figure 13A, seul spécimen en bon état de conservation, est comparable, par ses dimensions et sa morphologie générale, à celle de la Faune principale à Ermoceras d'Arabie Saoudite centrale figurée par Alméras (1987: pl. 5, fig. 7). Sa commissure frontale et ses commissures latérales se situent toutefois dans un seul et même plan. Son épaisseur est légèrement inférieure à sa largeur $(E / 1=0,89)$. Elle possède un gros crochet large, non crêté latéralement, recourbé et en contact avec l'umbo dorsal. Symphytium non exposé, masqué par le recourbement du crochet. 
TABLEAU 4. - Valeurs moyennes et intervalles de variation des dimensions chez diverses populations de Telothyris jauberti (Deslongchamps,1863). Abréviations: 1, spécimens rectimarginés de Khechem El Kelb, niveau KEK.2; 2, spécimens plissés de Khechem El Kelb, niveau KEK.2 ; 3 , spécimens plissés collectés dans tous les niveaux de Khechem El Kelb ; 4,1+2; 5, spécimens rectimarginés et plissés de Châabet El Attaris, niveau CHA.1; 6 , populations de Provence méridionale, forme type (données de Alméras \& Moulan 1982); 7, populations de la Bordure sud du Massif Armoricain, avec 46 exemplaires rectimarginés et 26 exemplaires planoplissés (données de Alméras et al. 2010a: tableau 9).

\begin{tabular}{|c|c|c|c|c|c|c|}
\hline & $\mathbf{N}$ & $\mathbf{L}$ & I & $\mathbf{E}$ & $\mathrm{I} / \mathrm{L}$ & $E / L$ \\
\hline 1 & 60 & $20,6(11,8-28,8)$ & $18,4(11,8-25,5)$ & $10,9(5,8-16,7)$ & $0,89(0,75-1,00)$ & $0,53(0,46-0,60)$ \\
\hline 2 & 26 & $24,7(20,0-32,0)$ & $20,0(18,1-27,0)$ & $13,6(10,5-17,9)$ & $0,84(0,77-0,92)$ & $0,55(0,49-0,63)$ \\
\hline 3 & 45 & $24,7(19,9-32,0)$ & $21,1(17,3-27,0)$ & $13,7(9,8-19,7)$ & $0,85(0,77-0,92)$ & $0,55(0,48-0,63)$ \\
\hline 4 & 86 & $21,8(11,8-32,0)$ & $18,9(11,8-27,0)$ & $11,7(5,8-17,9)$ & $0,88(0,75-1,00)$ & $0,54(0,46-0,63)$ \\
\hline 5 & 37 & $23,7(11,9-31,3)$ & $20,3(10,6-29,4)$ & $12,8(5,1-18,0)$ & $0,86(0,70-1,00)$ & $0,53(0,43-0,62)$ \\
\hline 6 & 126 & $29,9(16,8-43,7)$ & $25,4(15,4-32,5)$ & $17,8(10,5-26,2)$ & $0,85(0,70-0,97)$ & $0,61(0,53-0,71)$ \\
\hline 7 & 72 & $21,1(11,0-33,8)$ & $19,0(10,0-30,1)$ & $10,1(4,7-18,8)$ & $0,90(0,79-1,04)$ & $0,47(0,40-0,58)$ \\
\hline
\end{tabular}

Sous-ordre TEREBRATELLIDINA Muir-Wood, 1955

Super-famille ZEILLERIOIDEA Allan, 1940

Famille ZeILlERIIDAE Allan, 1940

Sous-famille VECTELLINAE

Mackinnon, Lee, Baker, Smirnova, Dagys \& Sun, 2006

Genre Ornithella Deslongchamps, 1884

ESPÈCE TYPE. - Terebratula ornithocephala J. Sowerby, 1812 par désignation originale (Deslongchamps 1884: 273).

\section{? Ornithella boxensis Muir-Wood, 1936}

(Fig. 13B)

Ornithella boxensis Muir-Wood, 1936: 112, pl. 5, fig. 10.

MATÉRIEL EXAMINÉ. — Khechem El Kelb, niveau KEK.33: spécimen de la Figure $13 \mathrm{~B}$ et peut-être deux autres coquilles incomplètement conservées et érodées.

DiMENSIONS. - PFT338, longueur $31 \mathrm{~mm}$, largeur $28 \mathrm{~mm}$, épaisseur $18,6 \mathrm{~mm}$ (Fig. 13B)

ÂGE eT RÉPARTITION. - L'espèce n'est connue que dans le Fuller's Earth Rock d'Angleterre (Bathonien moyen, zones à Subcontractus et à Morrisi). Sa variabilité n'étant ni illustrée, ni décrite, nous rapportons avec une certaine incertitude notre spécimen de Tunisie à l'espèce de Muir-Wood (crochet non crêté ; lamelles dentaires et septum non observés).

\section{DESCRIPTION}

Spécimen plus large que l'holotype du Wiltshire. Aspect du crochet recourbé et en contact avec l'umbo dorsal, petit foramen punctiforme sont des caractères présents sur l'holotype. Commissure frontale rectimarginée, commissures latérales rectilignes. Épaisseur modérée des valves moyennement renflées $(\mathrm{E} / \mathrm{L}=0,60)$.

\section{BIOSTRATIGRAPHIE ET PALÉOBIO- GÉOGRAPHIE DES BRACHIOPODES}

Malgré leur apparent isolement dans la partie centrale de la marge sud-téthysienne de l'Afrique, les brachiopodes rencontrés dans le Jurassique de l'Axe Nord-Sud se rapprochent tous de formes déjà connues par ailleurs, en particulier sur les marges nord et sud de la Téthys occidentale, mais également en Europe nord-occidentale (Fig. 14). Quelques éléments d'affinités arabiques s'y ajoutent au Jurassique moyen.

$\mathrm{Au}$ Toarcien inférieur et moyen, de la zone à Serpentinum, sous-zone à Levisoni à la zone à Bifrons, sous-zone à Sublevisoni, Homoeorhynchia batalleri, Quadratirhynchia vasconcellosi et Telothyris jauberti sont des espèces nordtéthysiennes répandues de la Provence méridionale aux deux versants des Pyrénées, aux Chaînes catalanes et ibériques et au Sous-bassin nord-lusitanien (rampe carbonatée de Tomar) (Alméras \& Fauré 2000). Ce domaine paléobiogéographique se superpose à l'ancien "biofaciès ibérique " de Choffat et Dubar (Dubar 1931). Ces mêmes espèces sont également abondantes sur la marge sud-téthysienne occidentale (Figs 14; 15B), du Maroc (Monts des Zekkara, Beni Snassen, Moyen-Atlas, Haut-Atlas central et oriental) à l'Algérie occidentale (Monts des Traras, de Rhar Roubane, de Saïda, Takhmaret, Ouarsenis) (Alméras et al. 2007a ; Alméras \& Fauré 2008). Jusqu'à présent, aucun témoin de cette faune n'était connu plus à l'Est. Pseudogibbirhynchia praedifformis, espèce uniquement rencontrée dans la souszone à Sublevisoni, montre le même type de répartition, bien qu'elle ne soit à ce jour connue qu'au Portugal et dans les Monts de Saïda, en Algérie occidentale.

Espèces plus anciennes, car présentes dans la seule sous-zone à Levisoni (zone à Serpentinum), Soaresirhynchia bouchardi et $S$. rustica sont plus ubiquistes. Si leur répartition sur les marges nord et sud de la Téthys occidentale est identique, elle recouvre également la bioprovince nord-ouest européenne où ces espèces sont fréquentes en Angleterre (Somerset, Dorset), en Allemagne (Wurtemberg) et en France, sur la Bordure sud du Massif Armoricain (Fig. 14). Pseudogibbirhynchia jurensis présente une répartition encore plus large en Angleterre (Oxfordshire, Cotteswolds) ; l'espèce est en outre fréquente dans le Quercy, sur la Bordure ardéchoise, dans le Jura méridional et l'Éperon lyonnais où elle est connue de la sous-zone à Elegantulum à la sous-zone à Bifrons.

Prionorhynchia msougari est une espèce sud-téthysienne (HautAtlas marocain, Ouarsenis) (Figs 14; 15B) dont l'extension verticale atteint la zone à Gradata dans le Haut-Atlas central. L'espèce est également signalée en France, dans le Toarcien moyen et le Toarcien supérieur basal condensé du Lyonnais (Éperon lyonnais, Mont d'Or) (Alméras et al. 1998). 

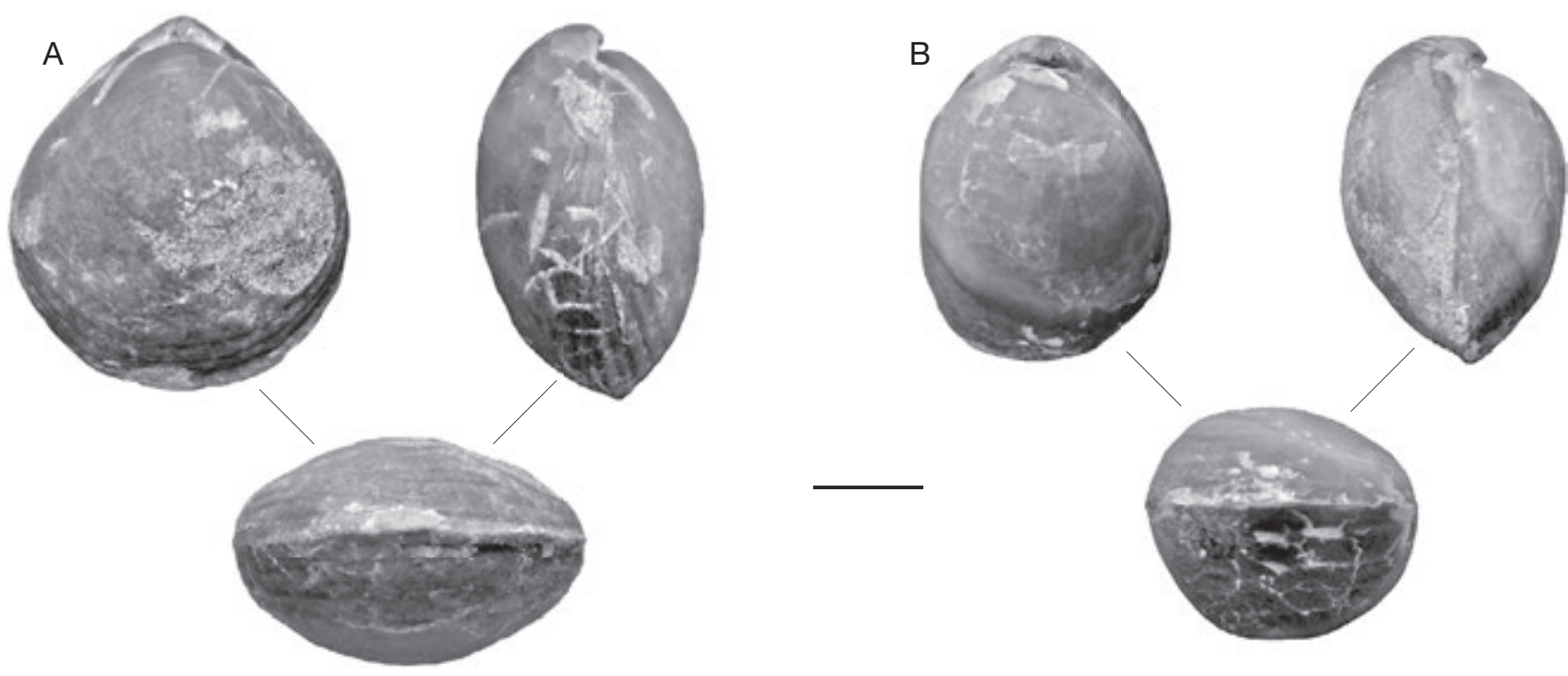

FIG. 13. - A, Tubithyris chouberti Rousselle, 1965, Bajocien inférieur, zone à Humphriesianum, Khechem El Kelb Est, niveau KEKE.14, PFT337 ; B, ? Ornithella boxensis Muir-Wood, 1936, Bathonien moyen, zone à Bremeri, Khechem El Kelb, niveau KEK.33, PFT338.

Au Bajocien inférieur, de la zone à Propinquans à la zone à Humphriesianum, Parvirhynchia parvula présente la même vaste répartition, de l'Europe moyenne (Mâconnais, Nièvre, Côte d'Or, Jura, Ile Crémieu, Mont d'Or lyonnais) aux Domaines Nord (Provence méridionale) et Sud téthysiens (Haut Atlas central marocain et Monts de Rhar Rhoubane, en Algérie occidentale) (Figs 14; 15B).

Burmirynchia termierae et Tubithyris chouberti, espèces connues dans les deux zones à Humphriesianum et à Niortense, présentent, quant à elles, une répartition essentiellement sud-téthysienne, étendue du Maroc (Moyen-Atlas, Hauts-Plateaux, Haut-Atlas central et oriental, Rides sud-rifaines) à l'Algérie occidentale (Monts de Rhar Roubane, Monts des Ksour occidentaux) et au Moyen-Orient (Jordanie, Sinaï, Negev et Arabie Saoudite) (Figs $14 ; 15 \mathrm{~B}$ ) où $B$. termierae est choisie comme espèce-indice de zone du Bajocien inférieur (Alméras et al. 2010b).

Au Bathonien inférieur, zones à Zigzag et à Aurigerus, Sphenorhynchia zraigensis et Ptyctothyris biplicata présentent aussi une répartition essentiellement sud-téthysienne, restreinte cette fois à la partie occidentale du domaine où elles sont connues du Maroc (Moyen-Atlas, Haut-Atlas central et oriental, Monts d'Oujda) à l'Algérie occidentale (Monts des Traras, de Rhar Roubane, de Saïda, Monts des Ksour occidentaux) (Figs 14; 15B).

La dispersion de Burmirhynchia athiensis est beaucoup plus large. L'espèce, abondante au Maroc et en Algérie occidentale, est aussi connue en Arabie Saoudite et sur la marge nord de la Téthys (Provence, Quercy) ainsi que, plus ponctuellement, dans la partie méridionale de l'Europe moyenne (Jura méridional et environs de Civaux, dans le département de la Vienne) (Figs 14; 15B).

Sphaeroidothyris lenthayensis (zone à Parvum) et Sphaeroidothyris elmii (zone à Bremeri) connues à ce jour dans les domaines nord-ouest européen (Jura, Normandie, Angleterre) et nord téthysien (Provence) (Fig. 14), n'avaient jamais été signalés sur la marge sud de la Téthys.

\section{ENVIRONNEMENTS DE DEPÔT}

Les séries réduites jurassiques de l'Axe Nord-Sud témoignent, entre le Pliensbachien et le Callovien, d'un domaine de plateforme peu profonde, structuré en horsts : la Plate-forme de Nara (Soussi 2002; Fig. 15A). Celle-ci est basculée vers le Sud sous l'effet d'une tectonique en distension active à partir du Toarcien supérieur, en rapport avec l'ouverture de la Téthys. Dans la partie septentrionale de l'Axe Nord-Sud, les environnements sont peu favorables aux brachiopodes, quasiment absents sur les coupes des Jebels Guéfaït et El Guemgouma, vraisemblablement en raison de fonds peu profonds, agités, sièges d'une sédimentation condensée, envahie par des faciès à oolithes ferrugineuses. Dans la partie méridionale de l'Axe Nord-Sud, les environnements de plate-forme externe, stable, bien oxygénée, sont durablement favorables à l'implantation et au développement des brachiopodes, nombreux sur les coupes des Jebels Sidi Khalif et Châabet El Attaris.

Au Toarcien inférieur-moyen, les alternances argiles-calcaires argileux blanchâtres à débit en boules, sont riches en gastropodes, bivalves, crinoïdes et brachiopodes. Ils correspondent à des dépôts de plate-forme externe néritique à hydrodynamisme modéré assurant oxygénation des eaux et renouvellement des apports trophiques. Les brachiopodes sont représentés par Telothyris jauberti (chez les Térébratulidés) et par Homoeorhynchia batalleri, Quadratirhynchia vasconcellosi et les espèces des genres Soaresirhynchia et Pseudogibbirhynchia (chez les Rhynchonellidés).

$\mathrm{Au}$ Bathonien inférieur et moyen, les brachiopodes ne réapparaissent de manière significative qu'avec les calcaires et calcaires argileux à filaments et Zoophycos, avec des environnements de plate-forme externe peu profonde, bien oxygénée, à hydrodynamisme localement assez élevé. Les Sphaeroidothyris lenthayensis (zone à Zigzag) et les Sphaeroidothyris elmii et Ornithella boxensis (zone à Bremeri) y montrent le même type de répartition paroxystique, en niveaux 


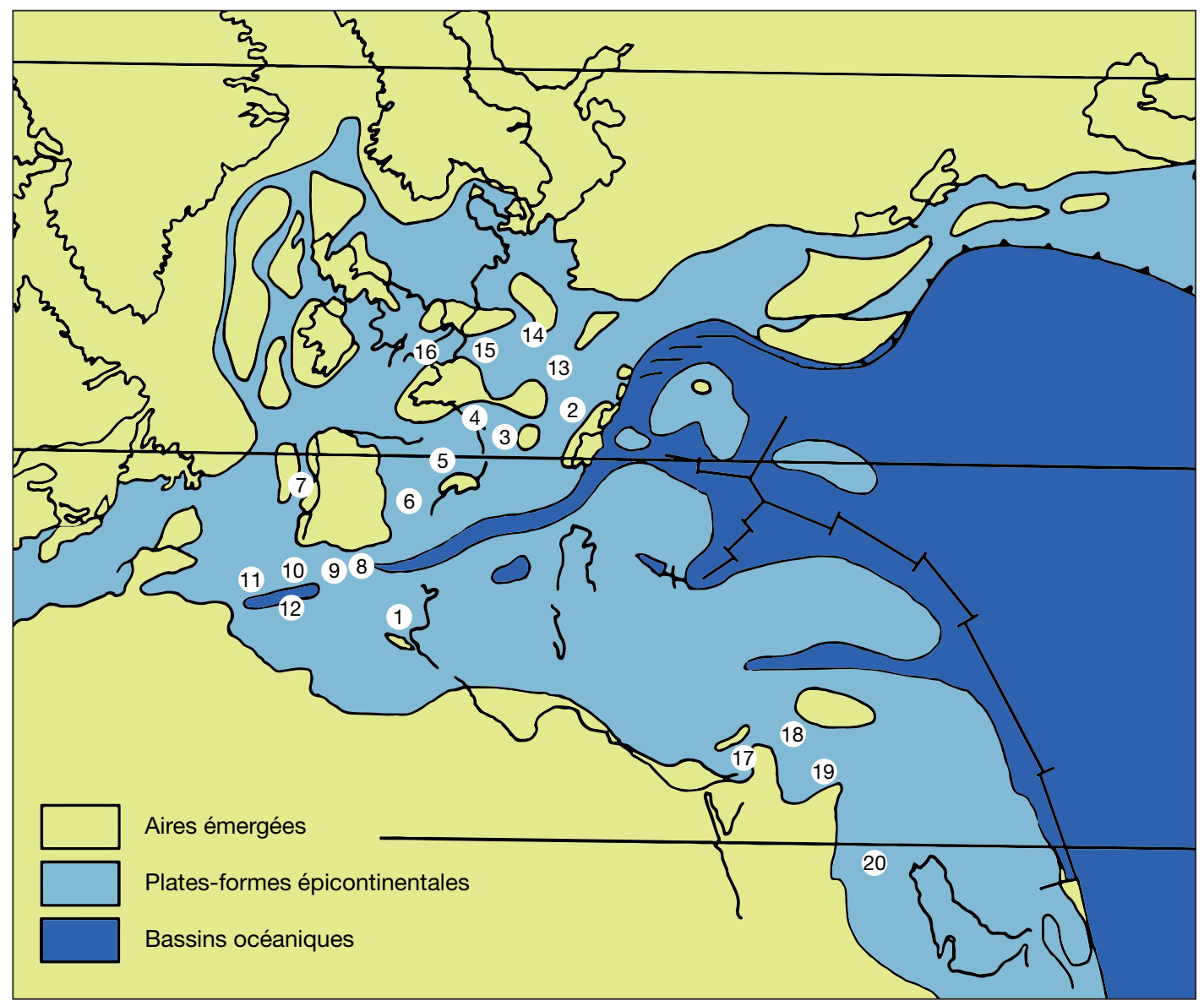

FIG. 14. - Distribution des brachiopodes étudiés, selon une carte paléogéographique simplifiée de la région péri-téthysienne au Jurassique moyen (d'après Thierry 2000) : 1, Axe Nord-Sud central ; 2, Provence méridionale ; 3, Quercy ; 4, Bordure sud-armoricaine ; 5, Pyrénées ; 6, Chaînes ibériques et catalanes ; 7, Sous-bassin nord lusitanien ; 8 , Ouarsenis ; $\mathbf{9}$, Algérie occidentale (Monts de Saïda et de Tlemcen) ; 10, Maroc oriental ; 11, Moyen Atlas ; 12, Atlas, Monts des Ksour ; 13, Lyonnais, Bourgogne, Jura ; 14, Wurtemberg ; 15, Normandie ; 16, Somerset, Dorset ; 17, Sinaï ; 18, Jordanie ; 19, Negev ; 20, Arabie Saoudite.

condensés, parfois en véritables biostromes, à faune monoou oligospécifique, séparés par des intervalles dépourvus de brachiopodes.

Les argiles à ammonites pyriteuses de la zone à Zigzag correspondent, au Bathonien inférieur, à un court épisode (sous-zone à Macrescens) de sédimentation marneuse, sur une aire géographiquement très limitée, évoquant une baie peu profonde, à sédimentation calme et protégée. La petite taille des brachiopodes Burmirhynchia athiensis, Sphenorhynchia zraigensis, voire leur miniaturisation, sont en rapport avec la faible oxygénation du fond marin due à la morphologie compartimentée de la plate-forme.

\section{IMPLICATIONS PALÉOGÉOGRAPHIQUES}

Tous ces Brachiopodes ouest-téthysiens ont en commun d'être associés à un même type de plate-forme continentale stable, peu profonde, bien oxygénée, sur laquelle se déposent des alternances argilo-carbonatées régulières, situées sur des cratons stables, tels que ceux entourant l'extrémité occidentale de la Téthys. Sur la marge sud de la Téthys occidentale, des environnements identiques existent du Maroc à l'Algérie occidentale, et sur sa marge nord, de la Provence aux Pyrénées, aux Chaînes ibéro-catalanes et au Portugal (Alméras \& Elmi 1993). Les paléoenvironnements de la Tunisie centrale sont de ce type.

Les connaissances, accumulées depuis de nombreuses années, sur la répartition paléobiogéographique des populations de brachiopodes de type ouest-téthysien (Elmi et al. 1982 ; Alméras \& Elmi 1993), en particulier sur la portion de marge sud-téthysienne comprise entre le Maroc et l'Algérie occidentale, nous éclairent sur la configuration paléogéographique de la Tunisie. Ajoutons que certaines espèces toarciennes se retrouvent dans les zones internes de la Cordillère bétique (Baeza-Carratalá et al. 2011). Les travaux de Soussi (2000, 2002), synthétisant les données de terrains et les nombreux apports de subsurface, permettent de reconnaitre (Fig. 15A):

- Au Sud, une plate-forme saharienne à faciès proximaux et détritiques appuyée sur le craton africain et bordée au Nord par le "Sillon des Chott " qui n'est autre que le prolongement oriental du Sillon atlasique ;

- Au Nord, un bassin pélagique subsident, à sédimentation radiolaritique, le Sillon tunisien, que l'on peut considérer comme le prolongement oriental du domaine tellien algérien ; 
B

Mer Méditerranée

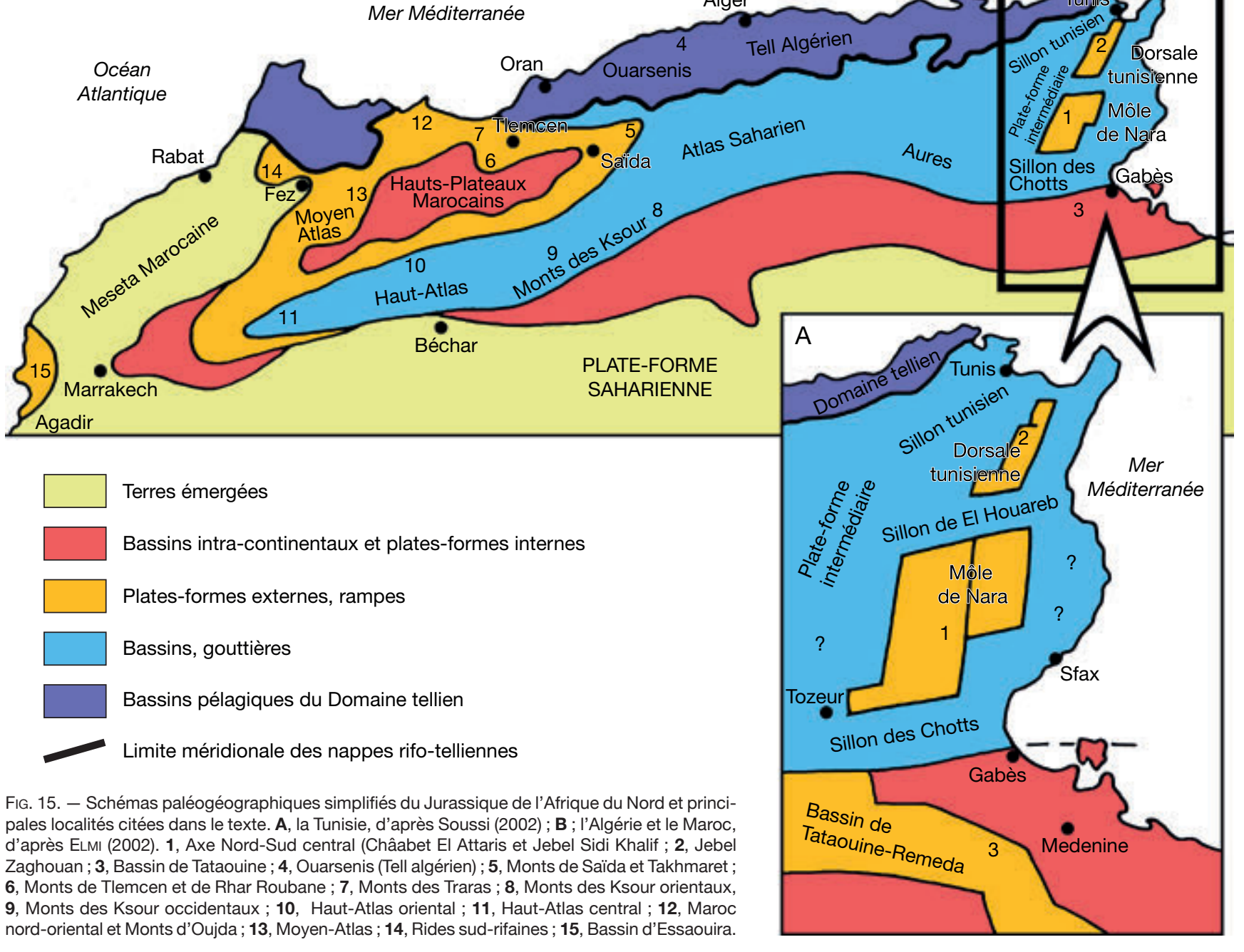

- Entre les deux zones, un « domaine intermédiaire " (Soussi 2002) constitué de plates-formes ou de haut-fonds, structurés en blocs basculés, séparés par des grabens plus ou moins subsidents. La plate-forme de Nara et la plate-forme de la Dorsale tunisienne en sont les deux éléments principaux.

Les faunes de brachiopodes ouest-téthysiens de l'Axe NordSud confirment les analogies déjà soulignées par les seules données sédimentologiques (Soussi 2002) entre la Plate-forme de Nara, en Tunisie centrale, et les domaines de plate-forme des Hauts Plateaux algéro-marocains (Piqué et al. 1998 ; Elmi 2002) (Fig. 15B). Leur configuration en horsts résistants y est identique, intermédiaire entre le sillon atlasique, au Sud, et les bassins pélagiques téthysiens, au Nord. Ces domaines de plate-forme ont été favorables, durant le Jurassique inférieur et moyen, à la migration des brachiopodes le long de la marge sud de la Téthys au travers de nombreux relais qui demeurent encore inconnus en Algérie centrale et orientale, jusqu’à leur implantation en Tunisie.

La plate-forme de la Dorsale tunisienne, située plus au Nord, appartient à ce même domaine intermédiaire structuré en horsts à partir du Toarcien supérieur (Fig. 15A). Pourtant, les brachiopodes de type ouest-téthysien y sont absents, en particulier dans la partie méridionale de la Dorsale (Jebels Zaress, Bent Saïdane, Staa) où les environnements de dépôts néritiques, à hydrodynamisme modéré, du Toarcien inférieur et moyen (absence, en particulier, des Soaresirhynchia), leur seraient à priori favorables (Fauré \& Peybernès 1986 ; Sekatni et al. 2008). Une telle absence peut trouver une explication dans la disposition paléogéographique particulière du «horst de la Dorsale " et par son isolement relatif des plates-formes intermédiaires plus méridionales dont elle est séparée par des fossés subsidents, dont «l'Hémi-graben d'El Houareb " (Soussi et al. 2000 ; Soussi 2002) (Fig. 15A).

Dans la partie septentrionale du "horst de la Dorsale " (Jebel Zaghouan), on trouve uniquement les brachiopodes de "type alpin " (Fauré et al. 2007) (Fig. 15A). Le Domérien supérieur terminal (zone à Emaciatum) y a livré de nombreux spécimens de Nannirhynchia pygmoea (Morris, 1847), espèce de petite taille, accompagnés de Apringia aptyga (Canavari, 1880), Linguithyris cornicolana (Canavari, 1881) et Bakonithyris apenninica (Zittel, 1869). Cette faune de " type alpin " possède une morphologie caractéristique : Rhynchonellidés non costés, de contour triangulaire (espèces 
axiniformes de Ager [1965], genre Apringia), Térébratulidés à plissement inverse (sinuation frontale des Linguithyris) et Zeilleriidés à commissure frontale également sinuée (genre Bakonithyris).

La répartition des brachiopodes de type alpin sur le pourtour méditerranéen a été révisée par Fauré et al. (2007). Ces faunes à large répartition géographique, sont partout caractéristiques d'environnements plus profonds, à sédimentation instable, au pied des plates-formes externes, sur la bordure de bassins en cours de fracturation (voir Fauré et al. 2007: fig. 9). En Tunisie, leur présence dans le Jebel Zaghouan est à relier avec sa position, sur la bordure du "Sillon tunisien ", élément de la marge nord-africaine de la Téthys en cours de fracturation. À noter que la «faune à Koninckella "du Toarcien inférieur basal (zone à Polymorphum), à laquelle est fréquemment associé Nannirhynchia pygmoea, n'a pas été observée.

\section{CONCLUSIONS}

En Tunisie atlasique, l'Axe Nord-Sud représente pendant le Toarcien un nouveau témoin, sur la marge sud de la Téthys, de la faune de brachiopodes dite ouest-téthysienne, dont les espèces présentent une large répartition, de la marge nord de la Téthys (de la Provence au Portugal) à la partie occidentale de sa marge sud (du Maroc à l'Algérie occidentale) (Figs 14; 15B). Aucun témoin de cette faune n'avait été décrit à ce jour sur la marge nord-africaine, à l'Est de l'Algérie occidentale, soit à près de $1000 \mathrm{~km}$ à l'Ouest de la Tunisie. Celle-ci élargi vers l'Est l'aire de répartition de cette faune.

En ce qui concerne les espèces sud-téthysiennes, comme Burmirynchia termierae, Tubithyris chouberti et Burmirhynchia athiensis, toutes sont à la fois connues du Maroc et de l'Algérie occidentale d'une part, et de la Province arabique $\mathrm{d}$ 'autre part où ces trois espèces sont largement représentées. La Tunisie constitue ainsi un jalon supplémentaire remarquable entre ces deux aires de répartition qui paraissaient très disjointes.

Ce type de répartition est un nouvel exemple de dispersion d'organismes benthiques à partir des régions arabiques le long de la marge sud-téthysienne, jusque dans la partie occidentale du Maghreb d'où elles atteignent l'Europe occidentale par le détroit ibéro-mauresque.

Cette voie d'échange fréquemment utilisée au Toarcien, au Bajocien et au Bathonien (Enay 1993), le sera à nouveau à partir du Callovien, période pendant laquelle des brachiopodes d'influence arabique ou éthiopienne (genres Daghanirhynchia et Bihenithyris notamment) vont à nouveau coloniser les plates-formes sud-tunisiennes (région de Tataouine) (Ben Ismail et al. 1989). Mais ces faunes resteront inféodées aux environnements proximaux qui règnent sur la seule plate-forme saharienne, le long de laquelle elles gagneront l'Algérie occidentale et le Maroc, jusqu'aux Bassins d'Essaouira et d'Agadir (Fig. 15B) (Peybernès et al. 1987).

\section{RÉFÉRENCES}

Ager D. V. 1962. - A monograph of the British Liassic Rhynchonellidae. Part 3. The Palaeontographical Society 116: 85-136.

Ager D. V. 1965. — The adaptation of mesozoic brachiopods to different environments. Palaeogeography, Palaeoclimatology, Palaeoecology 1: 143-172.

AHMAD F. 2000. - Middle Jurassic Brachiopoda faunas from Northwestern Jordan. Neues Jahrbuch für Geologische und Paläontologische Abhandlungen 2000 (5): 301-313.

AHMAD F. 2003. - Brachiopod faunas from the Middle Mughanniyya Formation of Wadi Shaban, Jordan. Neues Jahrbuch für Geologische und Paläontologische Abhandlungen 228 (1): 37-59.

AlmÉRAS Y. 1971. — Les Terebratulidae du Dogger dans le Mâconnais, le Mont d'Or lyonnais et le Jura méridional. Étude systématique et biostratigraphique. Rapports avec la paléoécologie. Documents des Laboratoires de Géologie de la Faculté des Sciences de Lyon 39: 690 p.

AlMÉRAS Y. 1987. - Brachiopodes du Lias et du Dogger: biostratigraphie et paléontologie, in ENAY R. (ed.), Le Jurassique d'Arabie Saoudite centrale. Geobios MS 9: 161-219.

ALMÉRAS Y. 1994. - Le genre Soaresirhynchia (Brachiopoda, Rhynchonellacea, Wellerellidae) dans le Toarcien du Sous-bassin nordlusitanien. Documents des Laboratoires de Géologie de Lyon 130: 135 p.

Alméras Y. 1996a. - The genus Pseudogibbirhynchia (Brachiopoda, Rhynchonellacea) from the Toarcian of Portugal, in COPPER P. \& JIN J. (eds), Brachiopoda. Proceedings of the third International Brachiopod Congress, Sudbury/Ontario/Canada/2-5 sept. 1995. A. A. Balkema edit., Rotterdam: 7-12.

AlMÉRAS Y. 1996b. - Les Brachiopodes toarciens et aaléniens inférieurs du Bassin du Rhône. Paléontologie et biostratigraphie. Révision de la collection Dumortier et compléments. Documents des Laboratoires de Géologie de Lyon 138: 1-123.

Alméras Y. \& Moulan G. 1982. - Les Térébratulidés liasiques de Provence. Paléontologie, biostratigraphie, paléoécologie, phylogénie. Documents des Laboratoires de Géologie de Lyon 86, 365 p.

Alméras Y. \& Lathuilière B. 1984. - Paléontologie et paléoécologie de Parvirhynchia parvula (Deslongchamps), brachiopode récifal et périrécifal du Bajocien moyen. Geobios 17 (6) : 797-822.

Alméras Y. \& Moulan G. 1988. — Les Térébratulidés du Dogger provençal (Paléontologie, biostratigraphie, phylogénie, paléoécologie). Documents des Laboratoires de Géologie de Lyon 101, 277 p.

AlmÉRAS Y. \& SADKI D. 1992. — Les Brachiopodes bajociens inférieurs du Haut-Atlas central au Sud de Midelt (Maroc) : Paléontologie et phénomène de miniaturisation. Revue de Paléobiologie 11 (1): 167-195.

AlméRAS Y. \& Elmi S. 1993. - Palaeogeography, physiography, palaeoenvironments and brachiopods communities. Example of the Liassic brachiopods in the Western Tethys. Palaeogeography, Palaeoclimatology, Palaeoecology 100 (1-2): 95-108.

Alméras Y. \& Fauré PH. 2000. - Les Brachiopodes liasiques des Pyrénées. Paléontologie, biostratigraphie, paléobiogéographie et paléoenvironnements. Strata, série 2, 36, 395 p.

Alméras Y. \& BÉCAUd M. 2002. - Les zones charnières entre provinces paléobiogéographiques. L'exemple des Brachiopodes de la Bordure sud du Massif Armoricain (France) au Toarcien. Géologie de la France 3: 17-29.

Alméras Y. \& Fauré PH. 2008. — Les Brachiopodes du Jurassique moyen sur la Marge sud de la Téthys occidentale (Maroc, Algérie occidentale). Paléontologie et échelles chronostratigraphiques. Revue de Paléobiologie 27 (2): 575-857.

Alméras Y. \& GuÉGAn J.M. 2009. - Les Térébratulidés et les Zeilleriidés du Jurassique moyen (Bajocien-Bathonien) de Normandie. L'Echo des Falaises 13 : 15-41.

Alméras Y., Ameur M. \& Elmi S. 1993. - Prionorhynchia regia (Rothpletz), Rhynchonellidé du Lias maghrébin et Evolution du genre Prionorhynchia Buckman. Bolletino della Società Paleontologica Italiana 32 (1): 59-77. 
Alméras Y., Mouterde R., Benest M., Elmi S. \& Bassoullet J. P. 1996. - Les Brachiopodes toarciens de la rampe carbonatée de Tomar (Portugal). Documents des Laboratoires de Géologie de Lyon 138: 125-191.

Alméras Y., Mouterde R., Benest M. \& Bassoullet J. P. 1997. — Biodiversité et stratégie A : l'exemple des Brachiopodes toarciens de la rampe carbonatée de Tomar (Portugal). Geobios, MS 21: 113-119.

Alméras Y. Combemorel R., Elmi S., Rulleau L. \& Tintant H. 1998. - Révision critique des Céphalopodes et des Brachiopodes décrits dans le tome IV (Toarcien, Aalénien) des « Études paléontologiques des dépôts jurassiques du Bassin du Rhône » par Eugène Dumortier (1874). Mémoires du Muséum d'Histoire Naturelle de Lyon 2, 208 p.

Alméras Y., Elmi S. \& Fauré Ph. 2007a. — Les Brachiopodes liasiques d'Algérie occidentale. Documents des Laboratoires de Géologie de Lyon 163: 241 p.

Alméras Y., Fauré Ph., Elmi S., Enay R. \& Mangold C. 2007b. Zonation des Brachiopodes du Jurassique moyen sur la Marge sud de la Téthys occidentale (Maroc, Algérie occidentale). Comparaison avec la Marge nord-téthysienne française. Geobios 40 (1): 1-19.

Alméras Y., BÉCAud M. \& COUgnON M. 2010a. — Brachiopodes liasiques de la Bordure sud du Massif Armoricain (Vendée, DeuxSèvres, France): Paléontologie et chronostratigraphie. Bulletin de la Société des Sciences naturelles de l'Ouest de la France, h.s. 2010-1, 131 p.

Alméras Y., Cougnon M., Enay R. \& Mangold C. 2010b. Brachiopodes du Jurassique inférieur et moyen d'Arabie Saoudite centrale. Paléontologie, Biostratigraphie et Paléoenvironnements. Échelles chronostratigraphiques. Documents des Laboratoires de Géologie de Lyon 168: 247 p.

ARNOULD-SAJET S. 1951. - Les ammonites pyriteuses du Tithonique supérieur et du Berriasien de Tunisie centrale. Annales des Mines et de la Géologie 10, 133 p.

Baeza-Carratalá J. F., García-Joral F. \& Tent-Manclús 2011. Biostratigraphy and paleogeographic affinities of the Jurassic brachiopod assemblages from Sierre Espuña (Maláguide Complex, Internal Betic Zones, Spain). Journal of Iberian Geology 37 (2): 137-151.

Ben Ismail M., Bouaziz S., Almeras Y., Clavel B., Donze P., EnAY R., GHemmi M. \& Tintant H. 1989. - Nouvelles données biostratigraphiques sur le Callovien et les faciès " purbeckowealdiens " (Oxfordien à Vraconien) dans la région de Tataouine (Sud-tunisien). Bulletin de la Société géologique de France 8 (V): 353-360.

Bonnefous J. 1972. - Contribution à l'étude stratigraphique et micropaléontologique du Jurassique de Tunisie (Tunisie septentrionale et centrale. Sahel, zone des Chotts. Thèse de doctorat d'État de l'Université de Paris VI, Paris, 397 p.

Boullier A. 1976. — Les Térébratulidés de l'Oxfordien du Jura et de la Bordure sud du Bassin de Paris. Thèse de Doctorat d'État de la Faculté des Sciences et Techniques de l'Université de Besançon, 110 et Annales scientifiques de l'Université de Besançon, 3ème sér., Géologie 27: 457 p.

BuCKMAN S. S. 1917. - The Brachiopoda of the Namyan Beds, Northern Shan States, Burma. Memoirs of the Geological Survey of India, Palaeontologia Indica, n.s. 3 (2), 299 p.

BuROLLET P. F. 1956. - Contribution à l'étude stratigraphique de la Tunisie centrale. Annales des Mines et de la Géologie 18: 93 p.

CASTANY G. 1951. - Étude géologique de l'Atlas tunisien oriental. Thèse de la Faculté des Sciences de Paris, Paris, 632 p.

Castany G 1952. - Atlas tunisien oriental et Sahel. XIXème Congrès géologique international. Monographies régionales. Alger 2ème série, 6: $152 \mathrm{p}$.

Dareste De la Chavanne J. 1930. — La région d'Oujda. Monographie paléontologique des faunes liasiques et jurassiques du Maroc nord-oriental (Brachiopodes, Echinodermes, Lamellibranches et Gastropodes). Notes et Mémoires du Service des Mines et de la Carte géologique du Maroc 16: 31-100.
DAVIDSON T. 1852. - A monograph of British Oolitic and Liasic Brachiopoda. Part 3, Conclusions. The Palaeontographical Society 6: 65-100.

DAVIDSON T. 1878. - A monograph of the British Fossil Brachiopoda. Supplement to the jurassic and triassic species. The Palaeontographical Society 32, part II (2): 145-241.

DELANCE J. H. 1969. - Étude de quelques Brachiopodes liasiques de Nord-Est de l'Espagne. Annales de Paléontologie, Invertébrés 55 (1): 1-44.

DeslONGCHAMPS E. E. 1862. — Études critiques sur des Brachiopodes nouveaux ou peu connus. Article 2: Espèces du Système Oolithique inférieur. Bulletin de la Société linéenne de Normandie, 3ème sér., 7: 274-279.

DeslongChamps E. E. 1863. - Études critiques sur des Brachiopodes nouveaux ou peu connus. Article 7 : Brachiopodes recueillis par M. De Verneuil dans le Lias de l'Espagne. Bulletin de la Société linéenne de Normandie, 3ème sér., 8 (1862-1863): 263-275.

Deslongchamps E. E. 1862-1885. - Paléontologie Française. Terrains jurassiques. 6. Brachiopodes. Masson édit., Paris, 448 p.

Dubar G. 1931. - Brachiopodes liasiques de Catalogne et des régions voisines. Bulleti del'Institucio catalano d'Historia natural, 2 ème sér., 31 (4): 103-180.

ELMI S. 2002. - L'Afrique du Nord au Jurassique. ATEIG-GFEJ International workshop sur le Jurassique de la marge maghrébine de la Téthys. ATEIG-GFEJ, Tunis: 266-274.

Elmi S., Alméras Y., Ameur M., Atrops F., Benhamou M. \& Moulan G. 1982. - La dislocation des plates-formes liasiques en Méditerranée Occidentale et ses implications sur les échanges fauniques. Bulletin de la Société géologique de France, XXIV (7): 1007-1016.

Elmi S., Alméras Y., Ameur M. \& Benhamou M. 1985. — Précisions biostratigraphiques et paléoécologiques sur le Lias des environs de Tiffrit (Saïda, Algérie occidentale). Cahiers de l'Institut Catholique de Lyon 14: 15-42.

ENAY R. 1993. - Les apports sud-téthysiens parmi les faunes jurassiques nord-ouest européennes: interprétation paléobiogéographique. Compte rendus de l'Académie des Sciences de Paris, série 2, 317: 115-121.

FAURÉ PH. \& PeYBernès B. 1986. - Biozonation par ammonites et essai de corrélation des séries réduites liasiques de la "Dorsale tunisienne ». Bulletin de la Société d'Histoire Naturelle de Toulouse 122: 41-49.

Fauré Ph., Espurt N. \& Alméras Y. 2004. - Précisions stratigraphiques sur le Trias et le Lias des Sierras Marginales occidentales du Haut-Aragon (Province de Huesca, Espagne). Implications structurales. Bulletin de la Société d'Histoire naturelle de Toulouse 140: 53-69.

Fauré Ph., Alméras Y., SeKatni N. \& Zargouni F. 2007. — Le Pliensbachien du Jebel Zaghouan. Nouvelles données faunistiques. Implications biostratigraphiques et paléobiogéographiques. Geodiversitas 29 (4): 473-506.

FLAMAND G. B. M. 1911. - Recherches géologiques et géographiques sur "Le Haut-Pays de l'Oranie " et sur le Sahara (Algérie et Territoires $d u$ Sud). Thèse Faculté des Sciences de l'Université de Lyon 47 et Rey édit., Lyon, 1001 p.

GarCía Joral F. \& GoY A. 2004. — Caracterizacion de Choffatirhynchia nov. gen. (Brachiopoda, Rhynchonellida) en el Toarciense (Jurasico) de la Cordillera Ibérica (Espana). Boletin del Real Societad Espanola de Historia natural (Sec. Geol.) 99 (1-4): 237-250.

García JORAL F., GOMEZ J. J. \& GOY A. 2011. - Mass extinction and recovery of the Early Toarcian (Early Jurassic) brachiopods linked to climate change in Northern and Central Spain. Palaeogeography, Palaeoclimatology, Palaeoecology 302 (3-4): 367-380.

GOURION A. 1960. — Révision de certains Brachiopodes liasiques de l'Ouest de l'Algérie. Bulletin du Service de la Carte géologique d'Algérie, n.s. 28 (1959): 61-148.

GoY A. 1974. - El Lias de la mitad Norte de la Rama Castellana de la Cordillera Ibérica (Espana). Thèse ès-Sciences de l'Université de Madrid, 1-3: $940 \mathrm{p}$. 
Groupe Français d’Étude du JuRAssique 1997. — Biostratigraphie du Jurassique ouest-européen et méditerranéen : zonations parallèles et distribution des invertébrés et microfossiles, in Cariou E. \& Hantzpergues P. (eds). Bulletin des Centres de Recherches Exploration-Production Elf-Aquitaine. Mémoire 17, 440 p.

HaAs H. 1889. - Kritische Beiträge zur Kenntniss der jurassischen Brachiopodenfauna des Schweizerischen Juragebirges und seiner angrenzenden Landestheile. Part 1. Mémoires de la Société Paléontologique Suisse 16: 1-35.

Muir-WOOD H.M. 1936. - A monograph of the Brachiopoda of the British Great Oolite Series. Part 1: The Brachiopoda of the Fuller's Earth. The Palaeontographical Society 89 (1): 144 p.

Néri C., Masetti D., Luciani V., Frabe M.C., Barbujani C., Handous H. \& ABDELhadi. 1991. - Analyse de faciès et encadrement séquentiel de la succession jurassique-crétacée du Djebel Nara (Axe N-S, Tunisie centrale). Memorie di Scienze Geologiche 43 : 261-292.

QUENSTEDT F. A. 1858. — Der Jura. Laupp édit., Tübingen: 824-842.

Peybernès B., Bouaduda M. S., Alméras Y., Ruget C. \& Cugny P. 1987. - Stratigraphie du Lias et du Dogger du bassin côtier d'Essaouira (Maroc) avant et pendant le début de l'expansion océanique dans l'Atlantique central. Comparaison avec le bassin d'Agadir. Compte rendus de l'Académie des Sciences de Paris, série 2, 305: 1449-1455.

Peybernès B, Kamoun F., Thierry J., Ben Youssef, M., Cugny P., Fauré Ph., \& Ghanmi M. 1995. - Séquences de dépôt et biochronozones d'Ammonites dans l'Intervalle Toarcien-Oxfordien de l'Axe N-S (Tunisie centrale). Compte rendus de l'Académie des Sciences de Paris, série 2a, 321: 593-600.

Piqué A, Brahim L. A., Ouali R. A., Amrhar M., Charroud M. Gourmelen C., LaVille E., RehKiss F. \& Tricard P. 1998. Évolution structurale des domaines atlasiques du Maghreb au Méso-Cénozoïque; le rôle des structures héritées dans la déformation du domaine atlasique de l'Afrique du Nord. Bulletin de la Société géologique de France 169: 797-810.

RAKUS M. \& GUEX J. 2002. — Les ammonites du Jurassique inférieur et moyen de la Dorsale tunisienne. Mémoires de Géologie 39, 217 p.
RichaRDSON L. \& WALKER J. F. 1907. — Remarks on the Brachiopoda from the Fuller's Earth. Quarterly Journal of the Geological Society 63 (4): 426-436.

RouSSELLE L. 1965. - Rhynchonellidae, Terebratulidae et Zeilleriidae du Dogger marocain (Moyen-Atlas, Hauts-Plateaux, Haut-Atlas). Notes et Mémoires du Service géologique du Maroc 187: 168 p.

Rousselle L. 1973. - Le genre Prionorhynchia (Rhynchonellacea) dans le Toarcien et l'Aalénien inférieur du Haut-Atlas central et oriental. Notes du Service géologique du Maroc 34 (n²54): 135-149.

SCHOELLER H. 1937. — Présence du Jurassique au SW de Kairouan (Tunisie). Comptes-rendus sommaires de la Société géologique de France: 156-157.

Sekatni N., Fauré Ph., Alouani R. \& Zargouni F. 2008. — Le Jebel Bou Kornine de Hammam Lif, témoin, dès le Toarcien supérieur, de la distension téthysienne. Comptes Rendus Palevol 7 : 185-194.

Soussi M. 2002. — Le Jurassique de la Tunisie atlasique. Stratigraphie, dynamique sédimentaire, paléogéographie et intérêt pétrolier. Documents des Laboratoires de Géologie de Lyon 157: $363 \mathrm{p}$.

Soussi M., Ben Ismaïl M. H. \& M'Rabet A. 1990. — Les « Black shales" toarciens de Tunisie centrale: témoins d'événement anoxique sur la marge sud téthysienne. Compte rendus de l'Académie des Sciences de Paris, série 2, 310: 591-596.

Soussi M., Enay, R., Mangold Ch., M'Rabet A., Rakus M. \& RABHI M. 1991. - Datations par ammonites des séries et des discontinuités du Jurassique de l'Axe Nord-Sud (Tunisie centrale). Compte rendus de l'Académie des Sciences de Paris série 2, 312: 501-507.

Soussi M., Enay R., Mangold Ch. \& Turki M. 2000. - The Jurassic events and their sedimentary and stratigraphic records on the Southern Tethyan margin in Central Tunisia, in CRASQUIN S. \& Barrier E. (eds), Peri-Tethys Memoir 5: new data on PeriTethyan sedimentary basins. Mémoires du Muséum national d'Histoire naturelle, Paris, 182: 57-92.

ThIERRY J. 2000. - Middle Toarcien (180-178 Ma), in CRASQUIN S. (ed.), Atlas Peri-Tethys, Paleogeographic Maps. Explanatory Notes. CCGM-CGMV, Paris: 61-70. 
APPENDICE 1. - Liste des genres étudiés.

Aromasithyris Alméras, 1971;

Burmirhynchia Buckman, 1917;

Homoeorhynchia Buckman, 1917;

Monsardithyris Alméras, 1971;

Ornithella Deslongchamps, 1884;

Parvirhynchia Buckman, 1917;

Prionorhynchia Buckman, 1917;

Pseudogibbirhynchia Ager, 1962;
Ptyctothyris Buckman, 1917;

Quadratirhynchia Buckman, 1917 ;

Soaresirhynchia Alméras, 1994;

Sphaeroidothyris Buckman, 1917;

Sphenorhynchia Buckman, 1917;

Telothyris Alméras \& Moulan, 1982;

Tubithyris Buckman, 1917. 
